\title{
El Niño teleconnection to the Euro-Mediterranean late-winter: the role of extratropical Pacific modulation
}

\author{
Marianna Benassi ${ }^{1}$ (D) $\cdot$ Giovanni Conti $^{1} \cdot$ Silvio Gualdi ${ }^{1,2} \cdot$ Paolo Ruggieri $^{1,3} \cdot$ Stefano Materia ${ }^{1}$. \\ Javier García-Serrano ${ }^{4,5}$. Froila M. Palmeiro . Lauriane Batté $^{6} \cdot$ Constantin Ardilouze $^{6}$
}

Received: 10 November 2020 / Accepted: 10 April 2021 / Published online: 3 May 2021

(c) The Author(s) 2021

\begin{abstract}
El Niño Southern Oscillation (ENSO) represents the major driver of interannual climate variability at global scale. Observational and model-based studies have fostered a long-standing debate on the shape and intensity of the ENSO influence over the Euro-Mediterranean sector. Indeed, the detection of this signal is strongly affected by the large internal variability that characterizes the atmospheric circulation in the North Atlantic-European (NAE) region. This study explores if and how the low-frequency variability of North Pacific sea surface temperature (SST) may impact the El Niño-NAE teleconnection in late winter, which consists of a dipolar pattern between middle and high latitudes. A set of idealized atmosphere-only experiments, prescribing different phases of the anomalous SST linked to the Pacific Decadal Oscillation (PDO) superimposed onto an El Niño-like forcing in the tropical Pacific, has been performed in a multi-model framework, in order to assess the potential modulation of the positive ENSO signal. The modelling results suggest, in agreement with observational estimates, that the PDO negative phase (PDO_) may enhance the amplitude of the El Niño-NAE teleconnection, while the dynamics involved appear to be unaltered. On the other hand, the modulating role of the PDO positive phase $\left(\mathrm{PDO}_{+}\right)$is not reliable across models. This finding is consistent with the atmospheric response to the PDO itself, which is robust and statistically significant only for PDO_. Its modulation seems to rely on the enhanced meridional SST gradient and the related turbulent heat-flux released along the Kuroshio-Oyashio extension. PDO_ weakens the North Pacific jet, whereby favoring more poleward propagation of wave activity, strengthening the El Niño-forced Rossby wave-train. These results imply that there might be conditional predictability for the interannual Euro-Mediterranean climate variability depending on the background state.
\end{abstract}

Keywords El Niño teleconnection $\cdot$ Pacific Decadal Oscillation $\cdot$ North Atlantic-European climate $\cdot$ Seasonal predictability

\section{Introduction}

This paper is a contribution to the MEDSCOPE special issue on the drivers of variability and sources of predictability for the European and Mediterranean regions at subseasonal to multiannual time scales. MEDSCOPE is an ERA4CS project co-funded by JPI Climate. The special issue was coordinated by Silvio Gualdi and Lauriane Batté.

Marianna Benassi

marianna.benassi@cmcc.it

1 Climate Simulations and Predictions Division, Fondazione Centro Euro-Mediterraneo sui Cambiamenti Climatici (CMCC), Bologna, Italy

2 Istituto Nazionale di Geofisica e Vulcanologia (INGV), Bologna, Italy
El Niño-Southern Oscillation (ENSO) is known to be a major driver of global climate variability at the interannual time scale, representing probably the most important source of seasonal predictability worldwide (e.g. Doblas-Reyes et al. 2013; McPhaden et al. 2006), and potentially also for the North Atlantic-European (NAE) sector (e.g. Dunstone et al. 2016; Mathieu et al. 2004; Scaife et al. 2014).

3 Dipartimento di Fisica e Astronomia (DIFA), Alma Mater Studiorum University of Bologna, Bologna, Italy

4 Group of Meteorology, Universitat de Barcelona (UB), Barcelona, Spain

5 Barcelona Supercomputing Center (BSC), Barcelona, Spain

6 CNRM, Université de Toulouse, Météo-France, CNRS, Toulouse, France 
Positive and negative ENSO phases lead to climate variability not only in the tropical region, but also in the extratropics. The atmospheric fingerprint and the mechanisms behind ENSO teleconnections have been widely discussed in the last decades (see Trenberth et al. 1998, for review). During positive ENSO phases, namely El Niño events, enhanced convection characterizes the central and eastern tropical Pacific, while suppressed rainfall is found in the western tropical Pacific. The former induces an anomalous diabatic heating distribution in the tropical troposphere, that triggers a circulation response extending from low to middle latitudes.

The El Niño teleconnection over the North Pacific-American sector is relatively well understood and characterized by a distinctive wave-train structure arching in the north-east direction from the tropical Pacific toward higher latitudes (e.g. Horel and Wallace 1981). The El Niño teleconnection over the NAE sector is less well established, as the detection of the signal is made difficult by the strong internal variability of the atmospheric circulation (e.g. Deser et al. 2017). Brönnimann (2007) reviewed and identified the canonical El Niño signature on the NAE circulation as characterized by a dipolar structure in sea level pressure between middle (negative anomalies) and high (positive anomalies) latitudes for the late-winter season (January-March; JFM). This is in agreement with the climatic signal correlated with the positive ENSO phase over the Euro-Mediterranean region, analyzed in an observational framework by Fraedrich and Müller (1992). This pattern is characterized by negative temperature anomalies over north-eastern Europe, below normal precipitation over Scandinavia, and enhanced rainfall over the Mediterranean sector. Nevertheless, this view is not universally accepted with many authors arguing nonlinearity (e.g. Hardiman et al. 2019; Jiménez-Esteve and Domeisen 2019) and seasonality (e.g. Park 2004; Mariotti et al. 2005; Shaman 2014; Ayarzagüena et al. 2018) in the ENSO influence.

The dynamics underlying the El Niño response over the NAE sector is likewise a matter of debate: different mechanisms have been considered including both tropospheric and stratospheric pathways. The tropospheric pathway may consist of both changes in the divergent circulation and in the rotational flow. On the one hand, the anomalous Walker circulation linked to a positive ENSO event is characterized by enhanced ascending motion over the central-eastern equatorial Pacific, and associated sinking over the western equatorial Pacific and the equatorial Atlantic. This anomalous zonal circulation is followed by a coherent anomalous meridional circulation, characterized in the tropical Atlantic by a weaker Hadley cell, impacting the Azores High and hence climate conditions over the NAE sector (Wang 2004). On the other hand, the rotational mechanism may involve the downstream propagation of large-scale Rossby wave-trains from the tropical Pacific (e.g. García-Serrano et al. 2011), the North Pacific (e.g. Honda et al. 2001), and of transient eddies over North America (e.g. Drouard et al. 2015; Jiménez-Esteve and Domeisen 2018; Li and Lau 2012). Stationary wave anomalies over the North Pacific-American sector result fully established in January (Bladé et al. 2008). The tail of this quasi-barotropic structure is consistent with the surface dipole over the North Atlantic, as discussed by Mezzina et al. (2020, 2021 - this Issue).

Complementarily, stratospheric dynamics is suggested to contribute significantly to the spread of the El Niño signal in the Northern Hemisphere. Planetary waves from the troposphere to the stratosphere impact the stratospheric polar vortex, leading to circulation anomalies which in turn propagate downward into the troposphere (Domeisen et al. 2019, and reference therein). At the surface, in the NAE sector, this signal projects onto a dipolar structure analogous to the observed El Niño fingerprint (e.g. Cagnazzo and Manzini 2009; Ineson and Scaife 2009).

As the main features of the El Niño teleconnection to NAE circulation have been widely explored in the last years, the potential non-stationary nature of this signal has progressively emerged (Rodríguez-Fonseca et al. 2016). The non-stationarity may be due to differences in the tropical forcing or in the teleconnection pathways (Yeh et al. 2018). For example, Toniazzo and Scaife (2006) link the sign of the NAE sea level pressure response to the intensity of El Niño, whereas Graf and Zanchettin (2012) emphasize the role of the El Niño diversity (Eastern-Pacific vs Central-Pacific El Niños) on the strength of the anomalies over Europe. On the other hand, both tropospheric (e.g. López-Parages et al. 2016a) and stratospheric (Rao et al. 2019) mechanisms may be affected by the low-frequency variability of the climate system. Some observational studies link the non-stationary El Niño signal over the NAE sector to lowfrequency variability in the tropical Atlantic (e.g. Gouirand and Moron 2003; Ham et al. 2014) and in the North Atlantic (e.g. Mariotti et al. 2002; López-Parages and RodríguezFonseca 2012). Non-stationarity in the El Niño impact on Euro-Mediterranean precipitation, resembling the signal in observations, has also been reported in long-term preindustrial simulations (López-Parages et al. 2015, 2016b). In both cases, it was linked to the modulating effect of lowfrequency modes of sea surface temperature (SST) variability, affecting the tropospheric mean circulation which in turn constraints the ENSO teleconnection. In a climate change perspective, it should be noticed how all the different modulating effects might be affected (e.g. Drouard and Cassou 2019; Soulard et al. 2019), possibly changing the extratropical ENSO response itself.

The aim of this study is to investigate if and how the El Niño teleconnection over the Euro-Mediterranean sector is modulated by low-frequency variability in the North 
Pacific SSTs. Different patterns of tropical SST anomalies are known to characterize the observed El Niño events (see Capotondi et al. 2015 for review), however we focus on the so-called conventional Eastern Pacific El Niño, for which robust extratropical atmospheric teleconnections have been reported (e.g. Trenberth et al. 1998; Alexander et al. 2002; Brönnimann 2007).

The Pacific decadal oscillation (PDO, Mantua et al. 1997) represents the most prominent mode of low-frequency climate variability in the North Pacific. It is defined as the leading empirical orthogonal function (EOF) of extratropical (northward of $20^{\circ} \mathrm{N}$ ) SSTs. It has both a direct impact on decadal climate variability locally (e.g. Latif and Barnett 1994) and globally (e.g. Trenberth and Fasullo 2013), and an indirect impact through modulation of interannual climate variability. The PDO effects on the extratropical ENSO teleconnection have been widely discussed (e.g. Dong et al. 2018; Gershunov and Barnett 1998) on the North PacificAmerican domain (McCabe and Dettinger 1999; Yu and Zwiers 2007) and on the East Asian sector (e.g. Wang et al. 2008). Some studies (e.g. Zanchettin et al. 2008; Ding et al. 2017) have also examined the effects on the NAE region, analyzing the ENSO signal (in its positive and negative phase respectively) in reanalysis data with respect to the observed PDO phases. Generally, these results suggest a potential intensification of the ENSO-NAE teleconnection when ENSO and the PDO are in phase. Yet, little modelling evidence has been shown on this subject, with the exception of López-Parages et al. (2015, 2016b) using free-running, coupled simulations. This study contributes to that need by performing targeted atmosphere-only simulations in a multimodel framework.

It should be noticed that the Pacific low-frequency variability could also be characterized by an inter-hemispheric pattern that includes tropical SST anomalies, i.e. the Interdecadal Pacific Oscillation (IPO), defined as the leading EOF applied to the entire Pacific basin (Zhang et al. 1997). However, only the northern extratropical component, namely the PDO pattern, is used in the sensitivity experiments performed here, since the focus is on the modulation of $\mathrm{El}$ Niño-NAE teleconnection via changes in the background flow without altering the tropical forcing. The El Niño forcing adopted in this study resembles a canonical Eastern Pacific El Niño pattern characterizing strong events in the observational period (e.g. Hardiman et al. 2019; see Sect. 2). Combining these idealized El Niño and PDO patterns allows to detect and attribute the response to the separate forcing applied, and hence to investigate El Niño teleconnection under different mean states, exploring the dynamical processes involved.

The manuscript is structured as follows: In Sect. 2 the models and the experimental setup are presented, in Sect. 3 the signal from the sensitivity experiments is described, while in Sect. 4 a tropospheric mechanism is proposed. The summary and discussion of the results are provided in Sect. 5.

\section{Model and experimental setup}

In this study we take advantage of a set of tailored sensitivity experiments designed in the framework of the ERA4CSfunded MEDSCOPE project. These atmosphere-only simulations have been performed prescribing a set of SST forcings, representative of different combinations of idealized $\mathrm{El}$ Niño and extratropical PDO patterns (Fig. 1). In addition, a reference control simulation forced with climatological SSTs (CTL), computed over the period 1981-2010, is considered.

The SST boundary conditions have been derived from the HadISST v2 reanalysis (Rayner et al. 2003). The El Niño pattern (EN; Fig. 1c) is defined using a linear regression of monthly SST anomalies onto the winter (December to February, DJF) NINO3.4 index over the reference climatological period (1981-2010); whereas the PDO pattern (PDO + Fig. 1a) is defined from a linear regression of annual SST anomalies onto the PDO index over the period 1900-2010, in order to better characterize the low-frequency variability. The negative PDO pattern (PDO_; Fig. 1b) is obtained by reversing the sign of $\mathrm{PDO}_{+}$. These anomalous SST patterns are superimposed to the climatological seasonal cycle; the positive and negative PDO patterns are kept constant and span the extratropical basin (from $20^{\circ} \mathrm{N}$ to $60^{\circ} \mathrm{N}$ ), while the El Niño pattern covers only tropical latitudes $\left(20^{\circ} \mathrm{S}-20^{\circ} \mathrm{N}\right)$ and has been amplified in order to have a maximum anomaly of about $2.7 \mathrm{~K}$ in winter (DJF), mimicking previous studies (e.g. Taguchi and Hartmann 2006) and comparable with strong events (i.e. 1982/1983, 1997/1998, 2015/2016).

Finally, in order to assess the potential modulating role of the low-frequency variability in the extratropical Pacific, another set of forcings is defined superimposing the El Niño pattern to the PDO anomalies, to both the positive (EN/ $\mathrm{PDO}_{+}$; Fig. 1b) and negative (EN/ PDO_; Fig. 1e) phases. For each experiment, a 50-member ensemble of one-year long integrations from the 1 st of June is performed. The atmospheric initial conditions for the sensitivity experiments are selected from CTL, which consists of a 50-year integration using perpetual radiative forcing at year 2000 (i.e. present-day conditions), after spin-up. The same constant radiative forcing is included also in the sensitivity experiments. A summary of the experimental setup adopted in this study can be found in Table 1 .

Three atmospheric general circulation models (AGCMs) followed the same protocol. These AGCMs are the atmospheric components of the $\mathrm{CMCC}$ seasonal prediction system version 3 (CMCC-SPS3, from now on CMCC; Sanna et al. 2016), CNRM-CM6-1 (from now on CNRM; Roehrig et al. 
2020; Voldoire et al. 2019), and EC-EARTH3.2 (from now on EC-EARTH; Davini et al. 2017; Haarsma et al. 2020). The main features of these AGCMs are reported in Table 2.
In the following sections, the analysis will be focused on the late winter season (i.e. JFM; see Sect. 1), and the difference between ensemble averages will allow to detect the
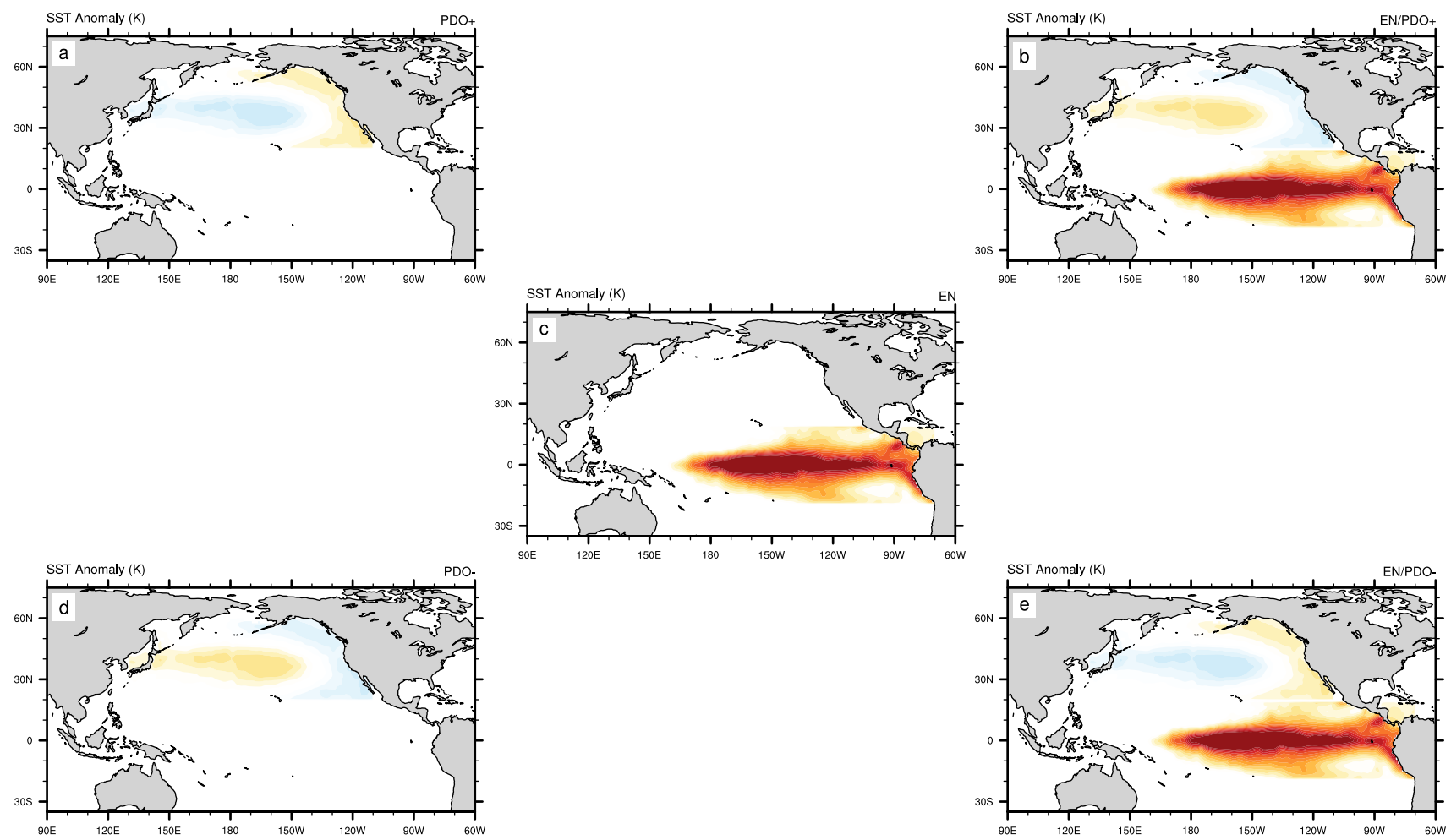

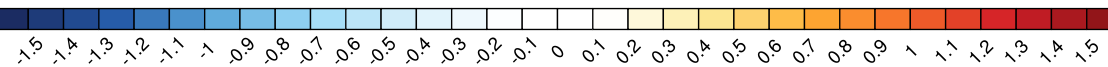

Fig. 1 Late winter (JFM) Sea Surface Temperature (SST) anomalies (K) superimposed on the climatological annual cycle for the different experiments: $\mathrm{PDO}_{+}(\mathbf{a}), \mathrm{PDO}_{-}(\mathbf{d})$, El Niño (c), El Niño/PDO + (b), and El Niño/PDO_(e). The PDO SSTs are included as a stationary forcing, while the El Niño forcing is modulated through an idealized seasonal cycle, peaking in DJF

Table 1 Summary of the experiments and experimental setup. In the following sections, the tags in the first column will be used to identify the different experiments

\begin{tabular}{|c|c|c|c|}
\hline Experiment name & SST forcing & Initialization & Duration \\
\hline CTL & Climatological SST & 20 years spinup & 50 years (recursive 2000 conditions) \\
\hline $\mathrm{EN}$ & El Niño over climatological SST & 50 1st June conditions from CTL & 12 months (June to May) \\
\hline $\mathrm{EN} / \mathrm{PDO}_{+}$ & El Niño and $\mathrm{PDO}_{+}$over climatological SST & 50 1st June conditions from CTL & 12 months (June to May) \\
\hline EN/PDO_ & El Niño and PDO_over climatological SST & 50 1st June conditions from CTL & 12 months (June to May) \\
\hline $\mathrm{PDO}_{+}$ & $\mathrm{PDO}_{+}$over climatological SST & 50 1st June conditions from CTL & 12 months (June to May) \\
\hline $\mathrm{PDO}_{-}$ & PDO_over climatological SST & 501 st June conditions from CTL & 12 months (June to May) \\
\hline
\end{tabular}

Table 2 Atmospheric components of the GCMs used in this study

\begin{tabular}{llll}
\hline GCM & Atmospheric component & $\begin{array}{l}\text { Horizontal resolu- } \\
\text { tion }(\mathrm{km})\end{array}$ & Vertical resolution \\
\hline CMCC-SPS3 & CAM5.3 & $\sim 110$ & 46 vertical levels $(0.3 \mathrm{hPa})$ \\
CNRM-CM6-1 & ARPEGE-Climat v6.3 & $\sim 150$ & 91 vertical levels $(0.01 \mathrm{hPa})$ \\
EC-EARTH3.2 & IFS cycle 36r4 & $\sim 80$ & 91 vertical levels $(0.01 \mathrm{hPa})$ \\
\hline
\end{tabular}


forced response of the system. Unless differently specified, the statistical significance of the analyzed signals has been evaluated by applying a Student's $t$ test of equal means at the $90 \%$ confidence level.

\section{Sensitivity patterns: modulation by the extratropical Pacific}

The experimental setup described in the previous section has been designed to capture potential changes in El Niño teleconnection under different mean state conditions associated with the different phases of the PDO. The analysis of the interaction between ENSO and PDO (e.g. Newman et al. 2003) is beyond the scope of this study. In this idealized framework, the two modes are considered as independent, and the focus is put on the potential modulating role of extratropical Pacific SSTs. Note that the atmospheric response to ENSO as such, in both its positive and negative phase, has been comprehensively reported in Mezzina et al. (2021).
Our assumption is that low-frequency variability of extratropical Pacific SSTs may influence the mid-latitude atmospheric circulation through which the El Niño teleconnection propagates. However, it has to be tested that the imposed PDO forcing does not affect the distribution of the tropical diabatic heating. Here we consider the rainfall response as a proxy for the anomalous diabatic heating due to the applied SST forcing. Figure 2 shows the precipitation response to $\mathrm{PDO}_{+}$(Fig. 2a, d, g), PDO_ (Fig. 2b, e, h) and El Niño (Fig. 2c, f, i). The latter is dominated by enhanced convection around the Date Line at equatorial latitudes, associated with the zonal shift of the Walker circulation. The precipitation anomalies due to the PDO phases do not collocate with, and are one-to-two orders of magnitude weaker than, the El Niño ones, confirming that the PDO-induced changes do not impact on the El Niño source region.

In an analogous way, Fig. 3 depicts the $200 \mathrm{hPa}$ zonal wind response to $\mathrm{PDO}_{+}$(Fig. 3a, d, g), PDO_ (Fig. 3b, e, h) and El Niño (Fig. 3c, f, i). As it is well known (e.g. DeWeaver and Nigam 2000), under El Niño conditions the
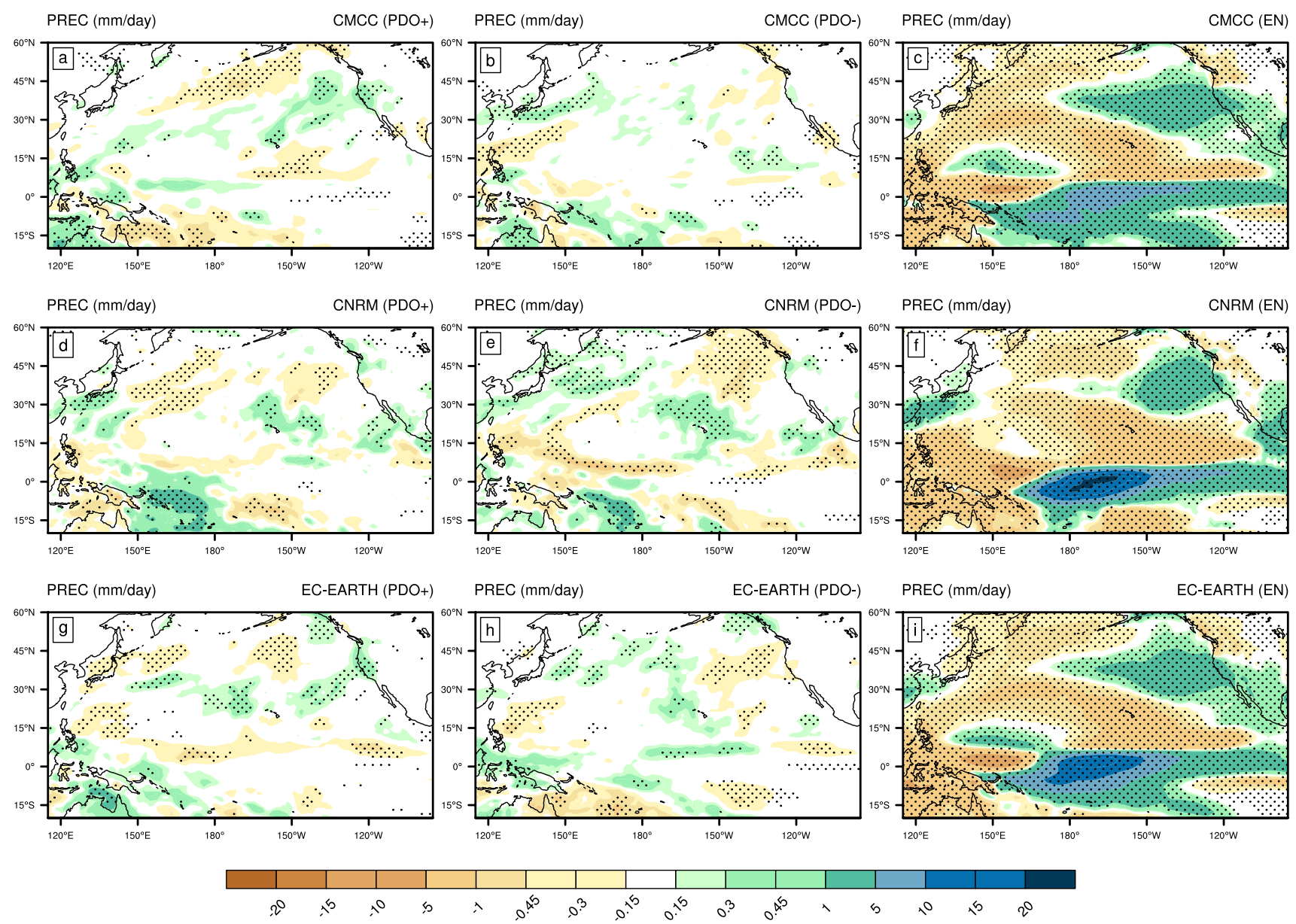

Fig. 2 Late winter (JFM) precipitation (mm/day) response to $\mathrm{PDO}_{+}$ (left column), PDO_ (middle column) and El Niño (right column) over the Pacific sector. Top row: results from CMCC model; mid- dle row: results from CNRM model; bottom row: results from ECEARTH model. The dotted regions are statistically significant at a $90 \%$ confidence level with a Student's t test 

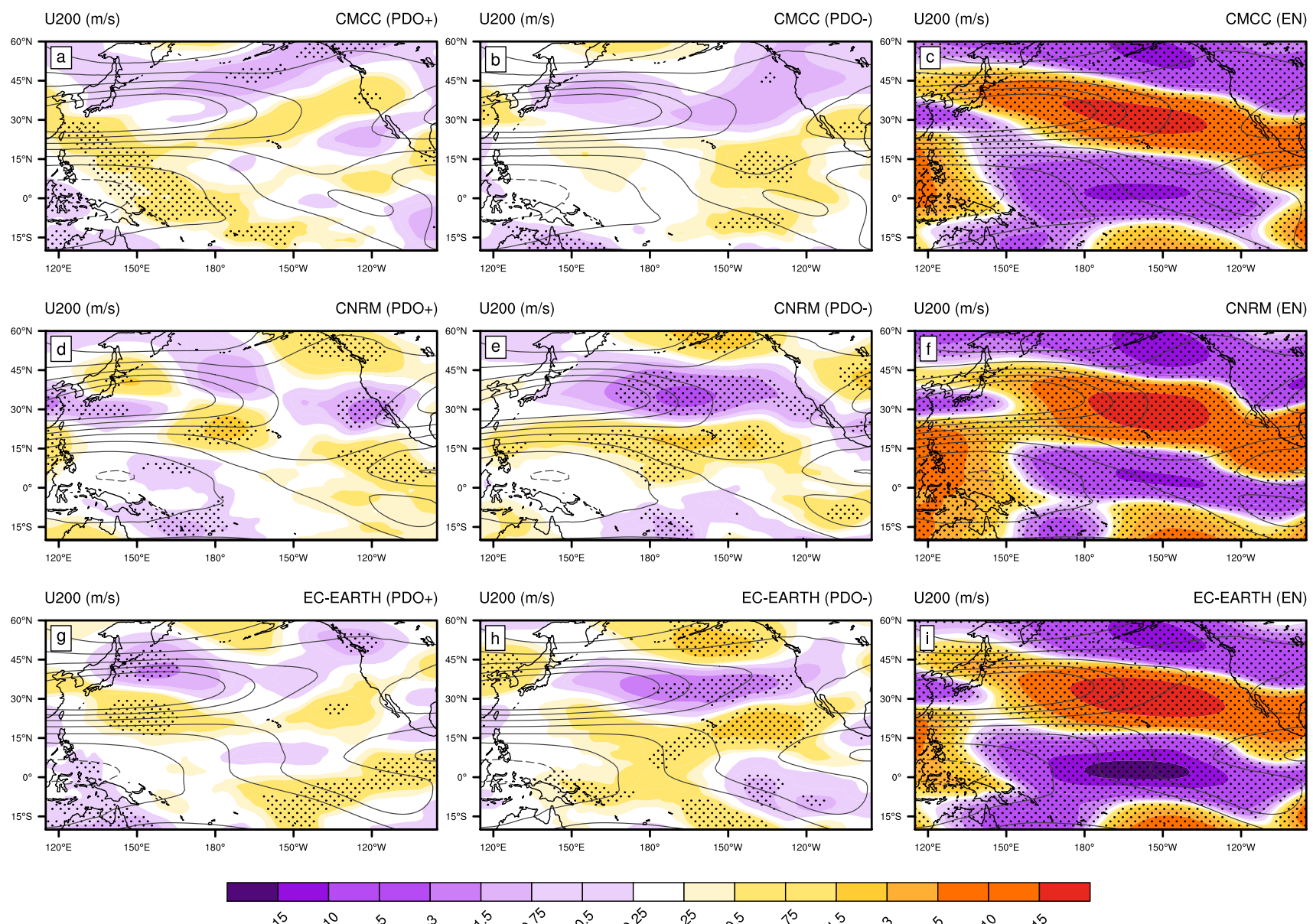

$i^{5} \quad \lambda^{0}$

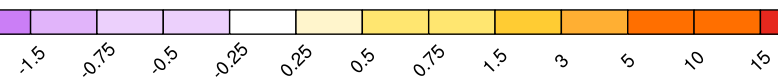

Fig. 3 Late winter (JFM) $200 \mathrm{hPa}$ zona wind (m/s) response to $\mathrm{PDO}_{+}$ (left column), PDO_ (middle column) and El Niño (right column) over the Pacific sector. The contours with dashed negative values represent the JFM climatological field computed from CTL experiment (from -20 to $50 \mathrm{~m} / \mathrm{s}$, contour interval: $10 \mathrm{~m} / \mathrm{s}$ ). Top row: results from CMCC model; middle row: results from CNRM model; bottom row: results from EC-EARTH model. The dotted regions are statistically significant at a $90 \%$ confidence level with a Student's t test
North Pacific jet tends to be stronger and extended eastward, which is properly captured by the three models. The mid-latitude upper-level response to the PDO is again one order of magnitude weaker than the El Niño one, but a distinct behaviour between the two phases can be found. While $\mathrm{PDO}_{-}$leads to a zonal wind pattern that is consistent among the three models (even if less robust for CMCC) and characterized by a weakening of the jet at its exit region, $\mathrm{PDO}_{+}$yields a more complex and less coherent signal in the multi-model ensemble. This preliminary analysis, further developed in Sect. 4, supports our initial hypothesis that even if the PDO were not changing tropical convection, it could affect the El Niño teleconnection by conditioning the mid-latitude background flow, particularly for PDO_

Observational data indicate that El Niño events may occur under both positive and negative PDO phases. In Fig. 4 the NINO3.4 and the PDO indices for the period 1900-2019 in the HadISST reanalysis are reported. Each El Niño event is indicated with a dot over the time series, while the dot color denotes the phase of the PDO for that event (red for $\mathrm{PDO}_{+}$ and blue for PDO_). The detection described above allows us to perform a composite analysis. Focusing on the historical period spanned by the NCEP reanalysis (i.e. 1948-2019; Kalnay et al. 1996), the El Niño winters are detected and divided into $\mathrm{PDO}_{+}$(12 events) and $\mathrm{PDO}_{-}$(9 events) conditions. This classification is summarized in Table 3. Although over the NCEP period the PDO index and the winter-mean NINO3.4 index have a weak correlation $(0.18$, but significant at the $95 \%$ confidence level), the comparable number of El Niño events under the two PDO phases provides some confidence to consider the two phenomena as independent for the purposes of this analysis.

Figure 5 shows the JFM mean sea level pressure anomalies for the El Niño conditions (Fig. 5a, d, g), as well as for El Niño under positive (Fig. 5b, e, h) and negative (Fig. 5c, f, i) PDO conditions. Here the contours represent the observational composites from the NCEP reanalysis, while the shading stands for the ensemble-mean response 


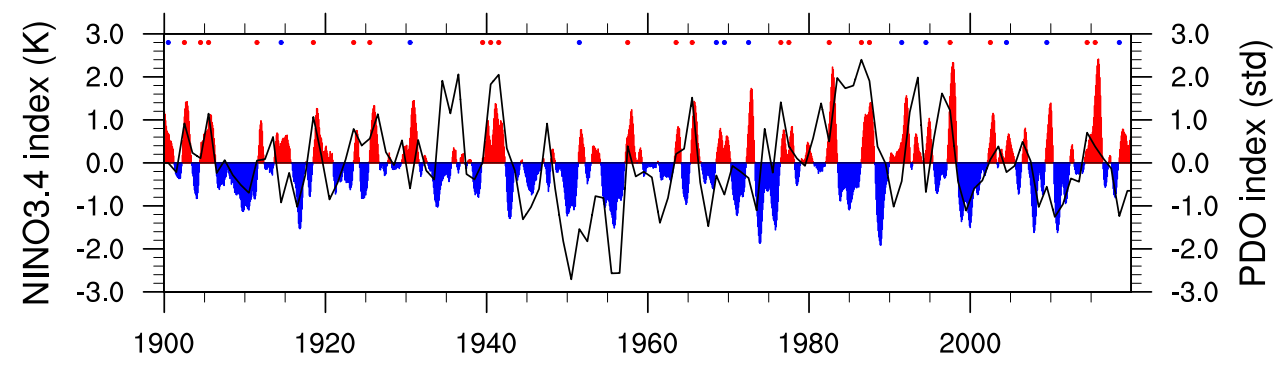

Fig. 4 Observed NINO3.4 (bar plot) and. PDO (black continuous line) indices computed in the HadISST reanalysis. The red and the blue dots highlight respectively the positive and negative PDO phase corresponding to each El Niño events over the period 1900 2019. Following Trenberth (1997), an El Niño event is detected when NINO3.4 index is greater than $0.4 \mathrm{~K}$ for at least six consecu-

from the idealized experiments described in Sect. 2: i.e. EN-CTL (Fig. 5a, d, g), EN/PDO + -CTL (Fig. 5b, e, h), EN/PDO__CTL (Fig. 5c, f, i). The extratropical teleconnection of El Niño (Fig. 5a, d, g) displays the canonical signatures, i.e. a deepening of the Aleutian Low in the North Pacific and a dipolar pattern in the NAE region (Brönnimann 2007). These features are well captured by the three models, with a slightly weaker signal in EC-EARTH (Fig. 5a, d, g; see Mezzina et al. 2021). As a first approximation, PDO conditions do not appear to change the structure of El Niño teleconnection but may affect its amplitude, suggesting that the same fundamental dynamics is at play. In agreement with Gershunov and Barnett (1998), in the reanalysis a decoupled modulation between the Pacific and Atlantic sectors may be noticed. In particular, $\mathrm{PDO}_{-}$shows a stronger Atlantic dipole and a damped low-pressure anomaly in the North Pacific (Fig. 5c, f, i), while for $\mathrm{PDO}_{+}$the changes in the teleconnection are generally less pronounced, with hints of a deeper Aleutian Low and a weaker high-pressure anomaly over Greenland (Fig. 5b, e, h). Also in the simulations, the presence of the PDO forcing, regardless of its phase, does not affect the overall shape of El Niño response (Fig. 5b, c, $\mathrm{e}, \mathrm{f}, \mathrm{h}, \mathrm{i}$ ), which confirms that the fundamental dynamics underlying the Northern Hemisphere atmospheric response to El Niño may not be modified by the presence of lowfrequency SST variability in the North Pacific. Likewise, it is to note that although the models simulate an apparent modulation in the amplitude of the Atlantic dipole, particularly for $\mathrm{PDO}_{-}$, this change is weak compared to the El Niño teleconnection.

Albeit the observational analysis points to a potential modulating role of the PDO, its limitations should be stressed, with emphasis on the small sampling compared to the target low-frequency variability and on the intrinsic difficulty to separate the different potential forcings in reanalysis. Moreover, with respect to the simulated response patterns, it should be highlighted that by construction they tive months. The correlation between PDO index and the JFM average NINO3.4 is 0.20 , considering the entire HadISST period (19002019), while it is 0.18 , focusing on the NCEP period (1948-2019). Both these values are statistically significant at the $95 \%$ confidence level

are influenced by the two forcings (El Niño and the PDO), hence their respective effect cannot be disentangled through a comparison with the climatological conditions (i.e. CTL). In other words, it is difficult to unambiguously diagnose whether the changes in the El Niño teleconnection, when the PDO is included, are due to the linear superposition of two forced signals or to the interaction of the El Niño forced signal with a different background state. The set of idealized simulations, however, allows to make a step forward in this regard. We can analyze explicitly the El Niño teleconnection under different mean states, computing the differences between each forced ensemble (EN, EN/PDO ${ }_{+}$, EN/PDO_) and the corresponding background condition $\left(\mathrm{CTL}, \mathrm{PDO}_{+}, \mathrm{PDO}_{-}\right)$. This approach allows to separate the response to El Niño without mixing effects of the PDO forcing itself, thereby defining three distinct El Niño teleconnection patterns with three different underlying conditions: EN-CTL, EN/PDO $+-\mathrm{PDO}_{+}$, EN/ PDO_- PDO_. In the following, in order to better identify the modulation, the differences between El Niño fingerprint under PDO and the benchmark teleconnection will be considered, namely (EN/ PDO-PDO)-(EN-CTL), for each phase of the PDO.

In Fig. 6 this approach is followed for mean sea level pressure: the left column (Fig. 6a, d, g) displays the reference EN-CTL signal (as in Fig. 5a, d, g), while the central and right columns show the changes in the teleconnection associated with positive (Fig. 6b, e, h) and negative (Fig. 6c, f, i) PDO conditions, respectively. In general, a coherent sign between the El Niño signal and the modulation pattern indicates that the El Niño fingerprint is intensified, while it is dampened if the two maps show an opposite sign. For $\mathrm{PDO}_{+}$the modulation appears not to be consistent across models, with two of them showing opposite responses (CNRM and EC-EARTH; Fig. $6 \mathrm{e}, \mathrm{h}$ ) and the third one being barely significant (CMCC; Fig. 6b). For PDO_, on the contrary, the three models agree on an amplification of the NAE response, showing low-pressure anomalies at mid-latitudes and high-pressure anomalies 


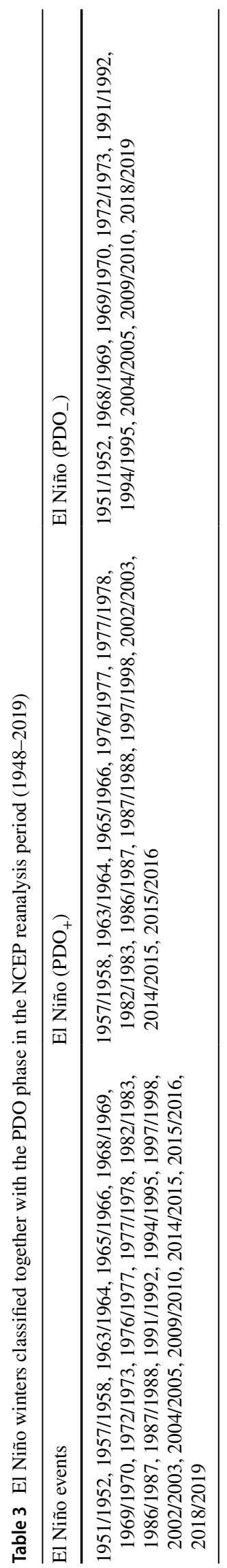

at subpolar/polar latitudes (Fig. 6c, f, i). However, this reinforcement is statistically significant in EC-EARTH (Fig. 6i), marginally significant in CNRM (Fig. 6f), and not significant in CMCC (Fig. 6c). A similar behaviour is found in the upperlevel circulation (not shown), revealing the barotropic nature of the teleconnection and of its potential modulation.

The El Niño-related atmospheric circulation in the North Atlantic sector is expected to drive surface climate anomalies over the Euro-Mediterranean region. As discussed in Bronnimann (2007) and Bronnimann et al. (2007), the canonical view of late winter El Niño teleconnection in this sector is characterized by cold and dry anomalies over northern Europe, an enhanced warming over eastern Mediterranean, and wetter conditions over the central-western Mediterranean. The MEDSCOPE multi-model fairly simulates these patterns in response to El Niño (EN-CTL; Figs. 7a, d, g, 8a, d, g shadings), in good agreement with observational composites (Figs. 8a, d, g; 9a, d, g contours). In line with the weaker circulation response in EC-EARTH (Fig. 5g), this model also shows weaker anomalies than CMCC and CNRM. The modulation of the El Niño signatures at the regional scale appear to be quite noisy, although somehow in agreement with the modulation of the circulation response (Fig. 6), particularly for precipitation. Under $\mathrm{PDO}_{+}$the model-dependent nature of the modulation pattern is confirmed (Fig. 7b, e, h); on the contrary, some consensus may be found under PDO_ with a comparable wetter Iberian Peninsula and a drier north-west Europe in CNRM (Fig. 7f) and EC-EARTH (Fig. 7i), as well as an expected noisier signal in CMCC (Fig. 7c), coherent with the not significant circulation pattern (Fig. 6c). The results for the $2 \mathrm{~m}$ temperature modulation (Fig. $8 \mathrm{~b}, \mathrm{c}, \mathrm{e}, \mathrm{f}, \mathrm{h}, \mathrm{i}$ ) are generally less conclusive, since large parts of the domain do not present statistically significant anomalies. Nevertheless, an enhanced cooling signal over Scandinavia under PDO_ is found in CMCC and EC-EARTH (Fig. 8c, i), and more weakly in CNRM (Fig. 8f).

Summarizing, the impact of a realistic PDO background state on the El Niño-NAE teleconnection seems to be of second order as compared to the El Niño signal, and also limited in statistical significance. Besides, the results suggest that there might be a conditional modulation according to the PDO phase, in particular for $\mathrm{PDO}_{-}$, resulting in an amplification of El Niño fingerprint. In the next section these results will be interpreted in a dynamical framework, investigating the differences between PDO phases, and providing a possible mechanism for the potential modulation. 

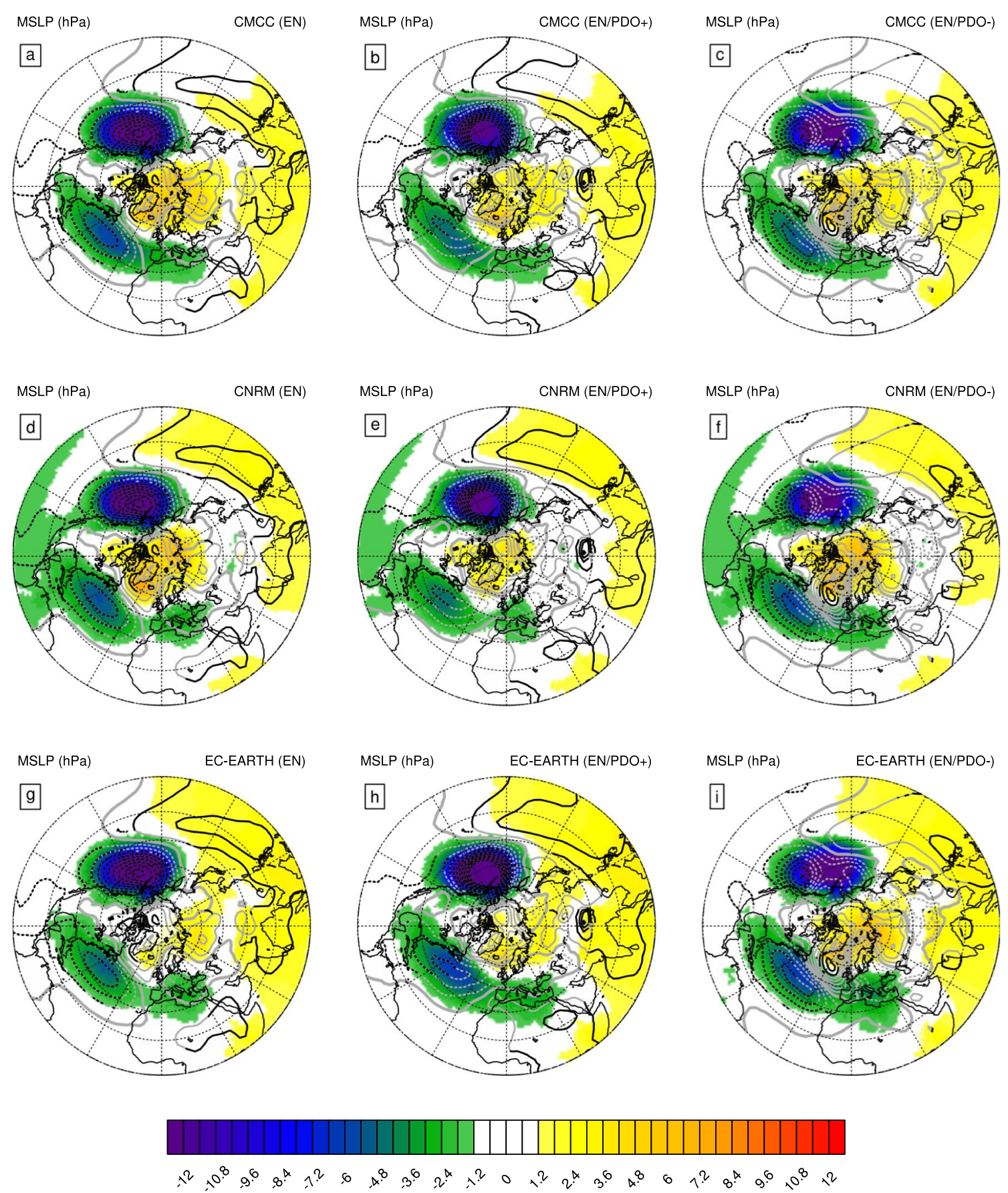

Fig. 5 Late winter (JFM) mean sea level pressure (hPa) El Niño composite from NCEP reanalysis (1948-2019) and in the multi-model ensemble. On the left: in shadings the reference El Niño teleconnection (EN-CTL) for CMCC (top), CNRM (middle), and EC-EARTH (bottom); in contours the composite computed over all the El Niño events (from -5.0 to $5.0 \mathrm{hPa}$, contour interval: $0.5 \mathrm{hPa}$ ). On the middle: in shadings El Niño and $\mathrm{PDO}_{+}$teleconnection $\left(\mathrm{EN} / \mathrm{PDO}_{+}-\mathrm{CTL}\right)$ for CMCC (top), CNRM (middle), and EC-EARTH (bottom); in contours the composite computed only over El Niño events under positive PDO phase (from -5.0 to $5.0 \mathrm{hPa}$, contour interval: $0.5 \mathrm{hPa}$ ). On the right: in shadings El Niño and PDO_ teleconnection (EN/PDO_
-CTL) for CMCC (top), CNRM (middle), and EC-EARTH (bottom), in contours the composite computed only over El Niño events under negative PDO phase (from -5.0 to $5.0 \mathrm{hPa}$, contour interval: $0.5 \mathrm{hPa}$ ). The detection of the El Niño events in the NCEP reanalysis is based on the analysis of the historical time series of NINO3.4 and PDO indices (see Table 3). For the composite analysis, black contours highlight regions with a signal statistically significant at $90 \%$ confidence level with a Cramer's test (as in Ding et al. 2017). For the multi-model ensemble, solid color areas represent signals which are statistically significant at $90 \%$ confidence level with a Student's $t$ test 

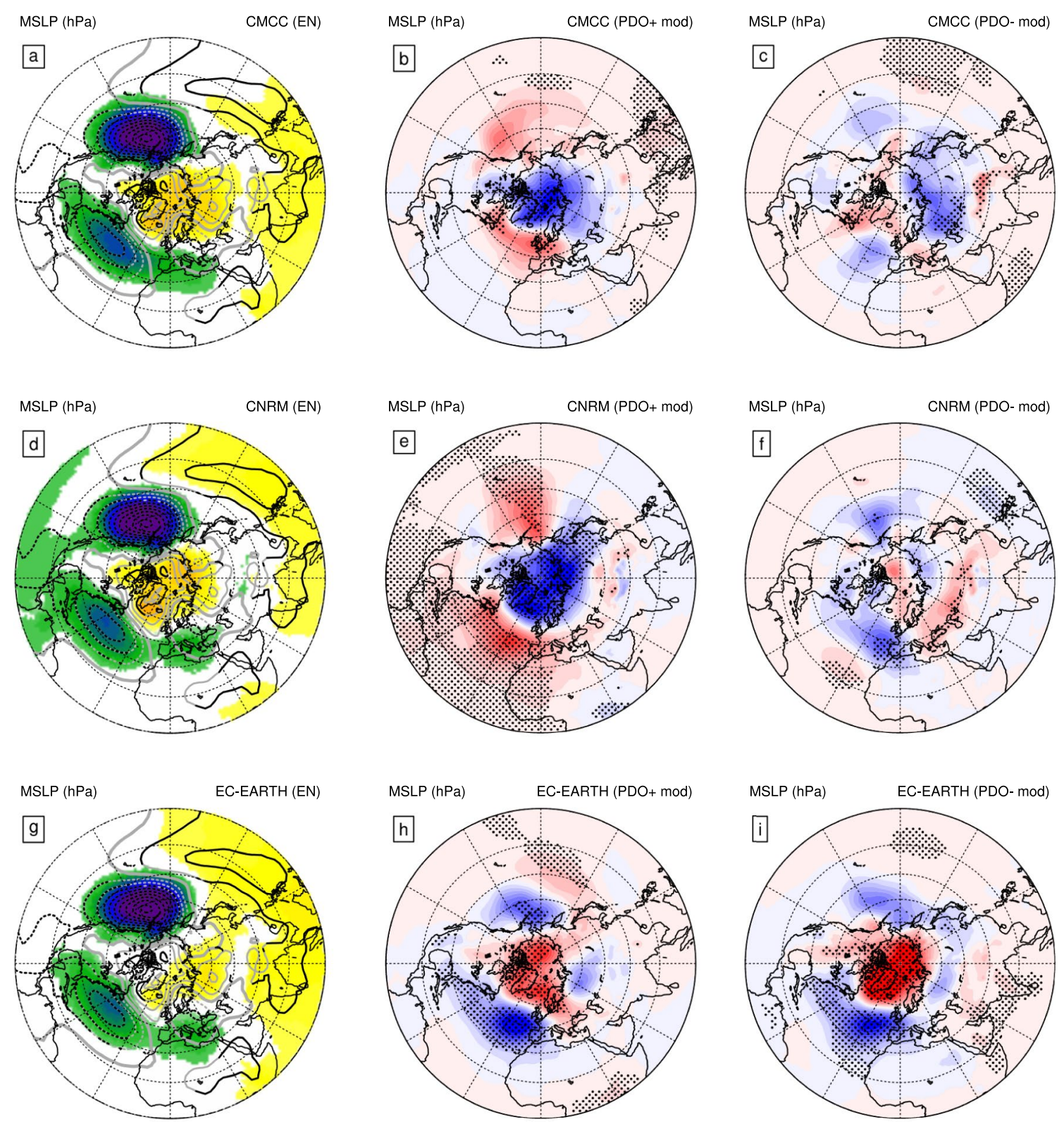

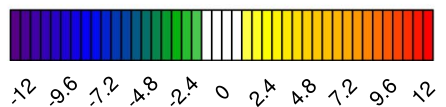

Fig. 6 Late winter (JFM) mean sea level pressure (hPa) teleconnection patterns and its modulation due to positive and negative PDO phases. On the left column: reference El Niño teleconnection (ENCTL) for CMCC (top), CNRM (middle), and EC-EARTH (bottom) (shadings) and in NCEP composite (contours from -5.0 to $5.0 \mathrm{hPa}$, contour interval: $0.5 \mathrm{hPa}$ ). On the middle column: modulation of El Niño teleconnection under positive PDO conditions ((EN/ $\left.\mathrm{PDO}_{+}-\mathrm{PDO}_{+}\right)-(\mathrm{EN}-\mathrm{CTL})$ ) for CMCC (top), CNRM (middle), and

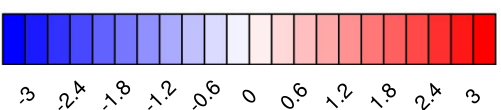

EC-EARTH (bottom). On the right column: modulation of El Niño teleconnection under negative PDO conditions ((EN/PDO_-PDO_)(EN-CTL)) for CMCC (top), CNRM (middle), and EC-EARTH (bottom). In the left column the statistical significance is indicated following the same convention as in Fig. 5. In the central and right columns, the dotted regions are statistically significant at $90 \%$ confidence level with a Student's t test 

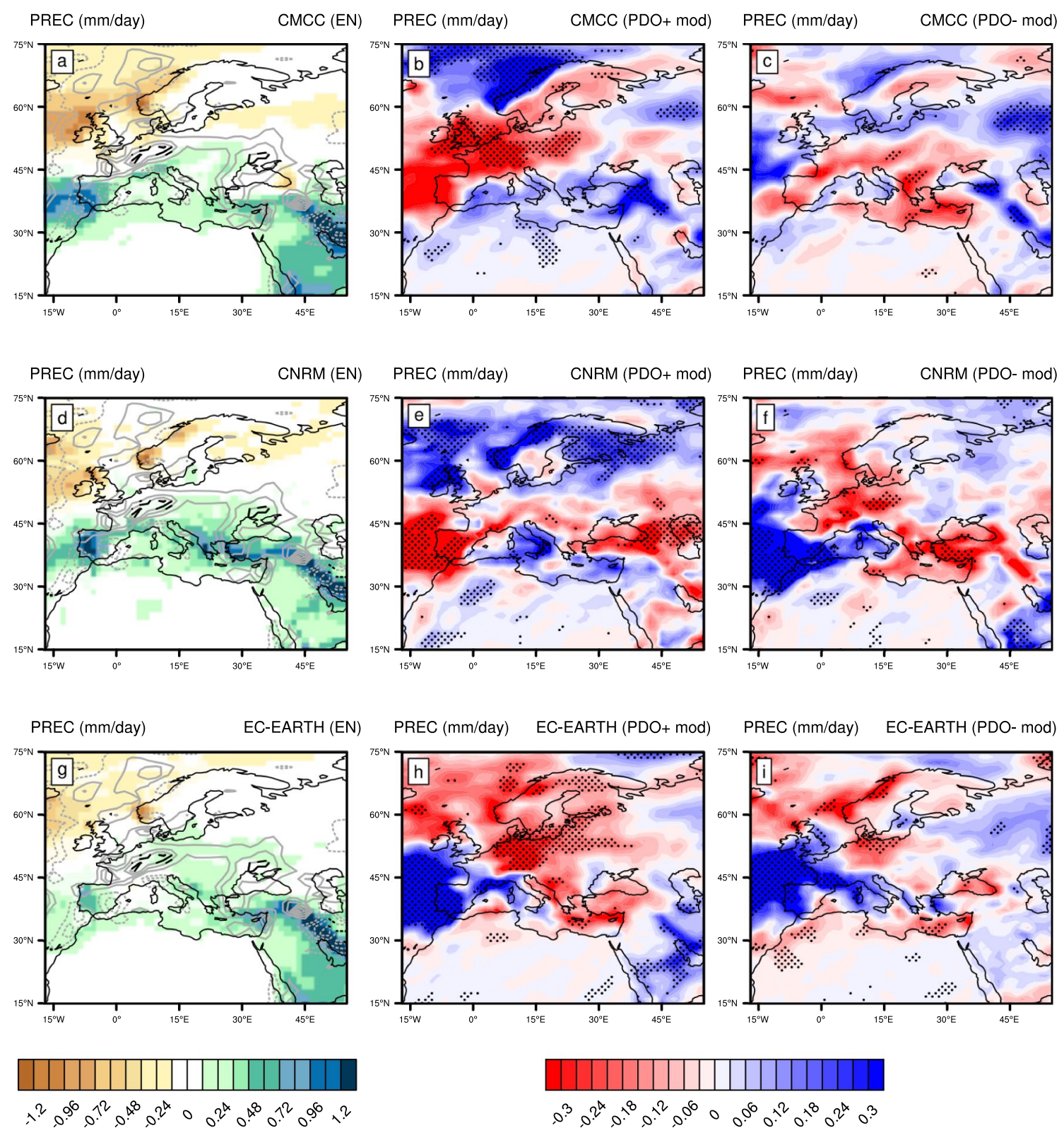

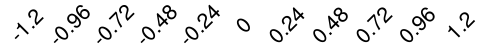

Fig. 7 Late winter (JFM) precipitation ( $\mathrm{mm} /$ day) teleconnection patterns over the Euro-Mediterranean sector and its modulation due to positive and negative PDO phases. On the left column: reference El Niño teleconnection (EN-CTL) for CMCC (top), CNRM (middle), and EC-EARTH (bottom) (shadings) and in NCEP composite (contours from -0.40 to $0.40 \mathrm{~mm} /$ day, contour interval: $0.08 \mathrm{~mm} /$ day). On the middle column: modulation of El Niño teleconnection under positive PDO conditions $\left(\left(\mathrm{EN} / \mathrm{PDO}_{+}-\mathrm{PDO}_{+}\right)-(\mathrm{EN}-\mathrm{CTL})\right)$ for $\mathrm{CMCC}$

\section{A tropospheric pathway for the ENSO teleconnection and its modulation}

The aim of this section is to provide insight into how the PDO may modulate the mid-latitude atmospheric background state through which the El Niño signal propagates. The mechanisms controlling the atmospheric response to

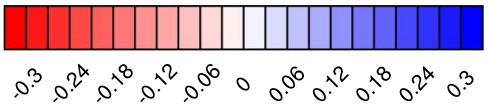

(top), CNRM (middle), and EC-EARTH (bottom). On the right column: modulation of El Niño teleconnection under negative PDO conditions ((EN/PDO_-PDO_)-(EN-CTL)) for CMCC (top), CNRM (middle), and EC-EARTH (bottom). In the left column the statistical significance is indicated following the same convention as in Fig. 5. In the central and right columns, the dotted regions are statistically significant at $90 \%$ confidence level with a Student's t test

an extratropical SST forcing have been widely discussed in the literature (e.g. see Kushnir et al. 2002 for review). In a recent study assessing the processes driving Pacific decadal variability (Luo et al. 2020), the authors show and discuss the local atmospheric fingerprint linked to the PDO based on observations and in a coupled model. With a composite analysis comparing the DJF response 

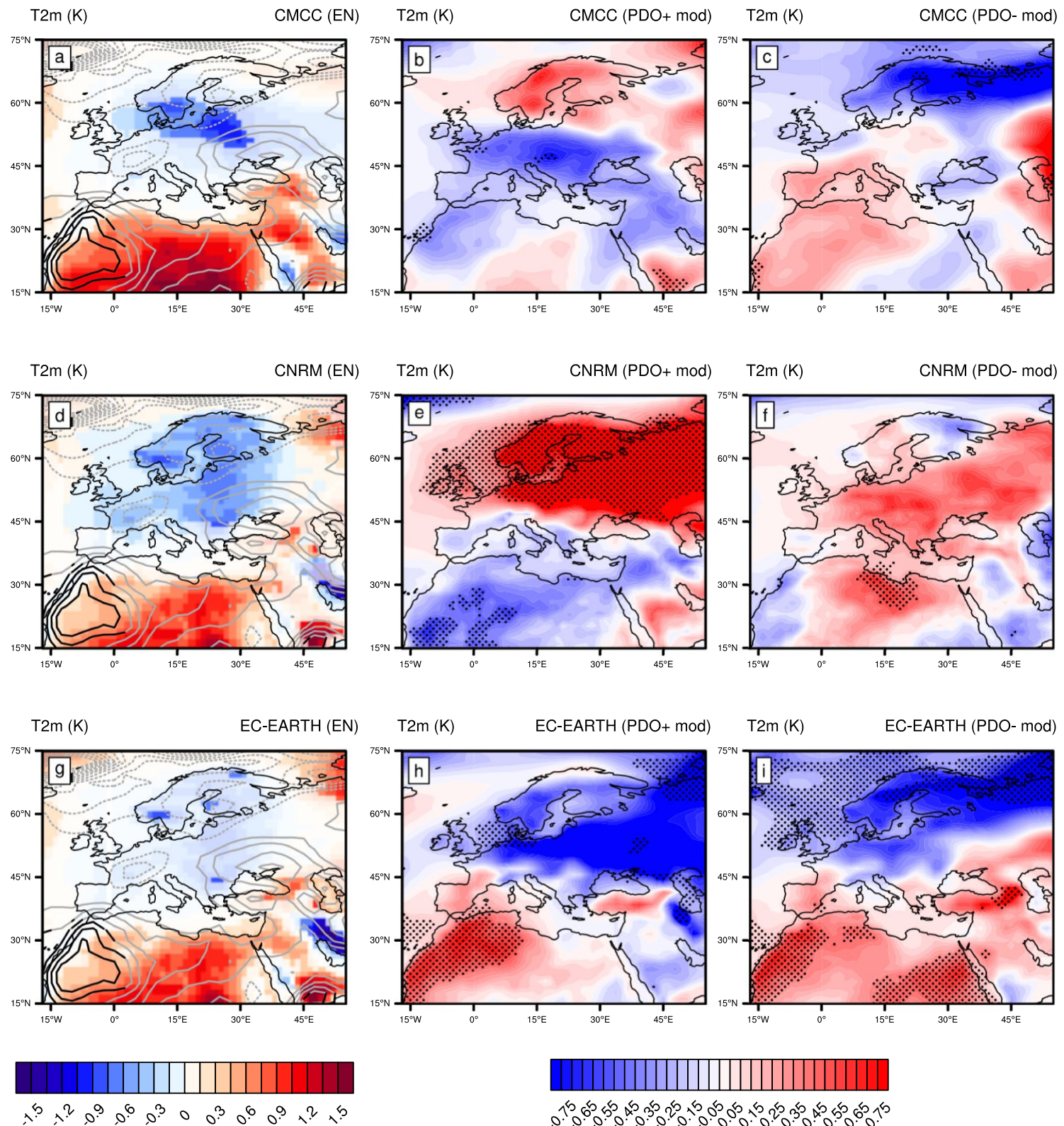

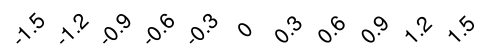

Fig. 8 Late winter (JFM) $2 \mathrm{~m}$ temperature $(\mathrm{K})$ teleconnection patterns over the Euro-Mediterranean sector and its modulation due to positive and negative PDO phases. On the left column: reference El Niño teleconnection (EN-CTL) for CMCC (top), CNRM (middle), and EC-EARTH (bottom) (shadings) and in NCEP composite (contours from -1.0 to $1.0 \mathrm{~K}$, contour interval: $0.1 \mathrm{~K}$ ). On the middle column: modulation of El Niño teleconnection under positive PDO conditions ((EN/PDO $\left.\left.-\mathrm{PDO}_{+}\right)-(\mathrm{EN}-\mathrm{CTL})\right)$ for CMCC (top), CNRM

to positive and negative PDO conditions, they identify an equivalent barotropic structure, characterized by a cyclonic circulation over the North Pacific, north-east of the cold SSTs. This extends from the surface to the upper levels, and it is accompanied by a cold temperature anomaly at the upper troposphere that reverses sign at the lower stratosphere.

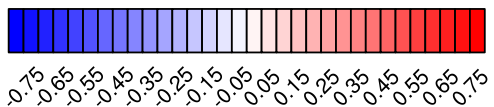

(middle), and EC-EARTH (bottom). On the right column: modulation of El Niño teleconnection under negative PDO conditions ((EN/ PDO-PDO_)-(EN-CTL)) for CMCC (top), CNRM (middle), and EC-EARTH (bottom). In the left column the statistical significance is indicated following the same convention as in Fig. 5. In the central and right columns, the dotted regions are statistically significant at $90 \%$ confidence level with a Student's t test

Figure 9 shows JFM circulation and temperature anomalies for positive and negative PDO conditions from the NCEP reanalysis at the same levels analyzed by Luo et al. (2020): i.e., surface, $850 \mathrm{hPa}, 500 \mathrm{hPa}$, and $100 \mathrm{hPa}$. These patterns have been obtained with a composite analysis including the 10 years with the more intense positive and negative values of the PDO index over the 1948-2019 NCEP period. 

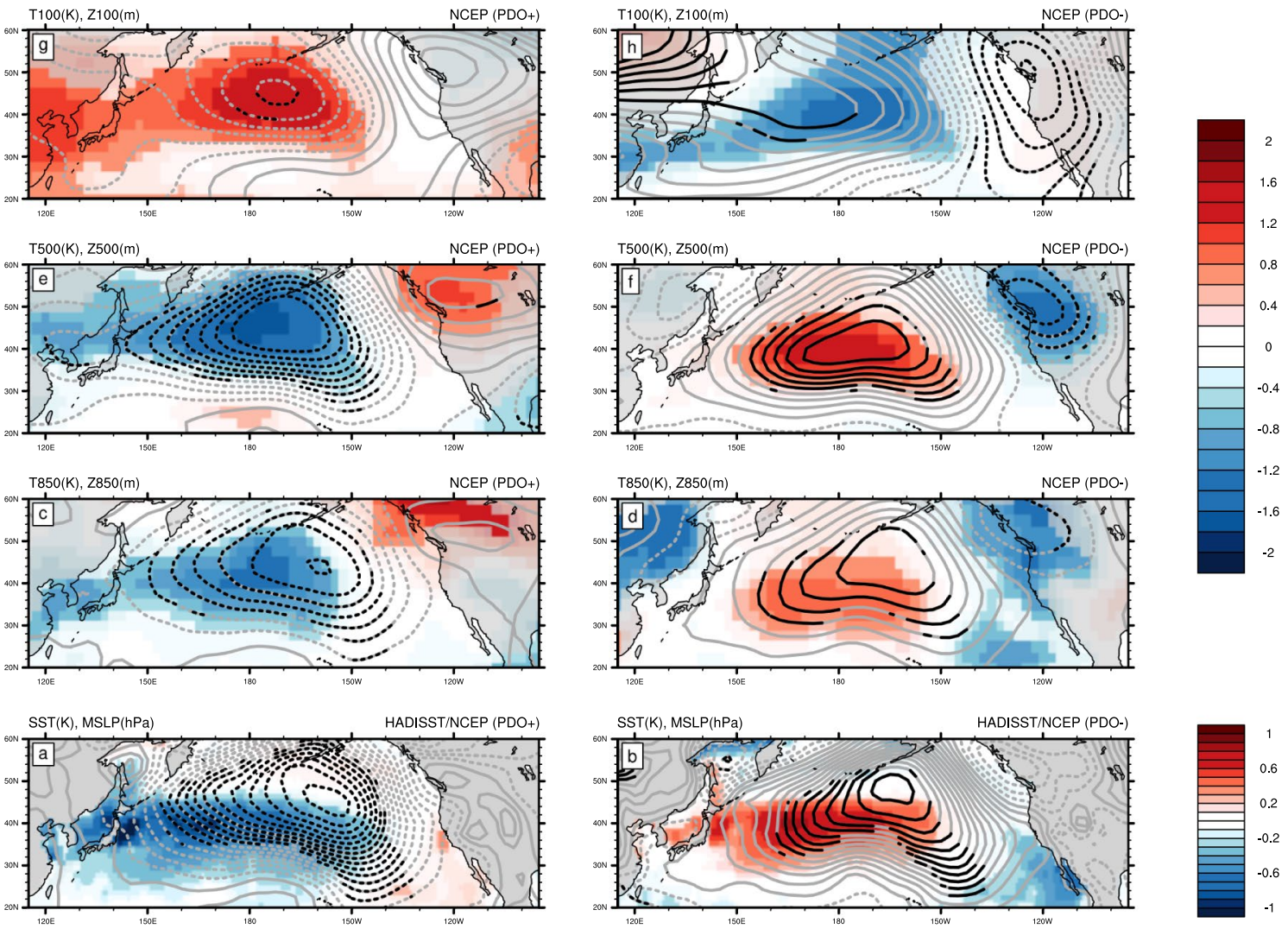

Fig. 9 Late winter (JFM) PDO composite response in HadISST and NCEP reanalysis at surface $(\mathbf{a}, \mathbf{b})$ and at different levels in the troposphere: $850 \mathrm{hPa}(\mathbf{c}, \mathbf{d}), 500 \mathrm{hPa}(\mathbf{e}, \mathbf{f})$, and $100 \mathrm{hPa}(\mathbf{g}, \mathbf{h})$, as in Fig. 2 of Luo et al. (2020). PDO and PDO_ signals are defined by considering the 10 years with the strongest positive (i.e. 1986, 1993, 1983, 1987, 1985, 1984, 1996, 1965, 1976, 1981) and negative (i.e. 1950, $1955,1956,1952,1949,1951,1967,1961,2010,2018)$ values of the PDO index over the NCEP period (1948-2019). The shading is for HadISST sea surface temperature $(\mathrm{K} ; \mathbf{a}, \mathbf{b})$ and NCEP air tempera-

In agreement with Luo et al. (2020), the patterns show a symmetry between the two PDO phases in terms of both amplitude and location of the main centers of action. In the multi-model framework, the response to positive and negative PDO SSTs are reported in Fig. 10 (i.e., PDO $_{+}-$CTL) and Fig. 11 (i.e., PDO_-CTL) respectively, revealing by contrast a substantial asymmetry in the response to the two opposite forcings. The $\mathrm{PDO}_{+}$patterns indicate that the atmospheric response is strongly model-dependent and essentially not statistically significant, showing wave-like anomalies of different polarity and orientation (Fig. 10). On the contrary, the $\mathrm{PDO}_{-}$signature is consistent across the multi-model ensemble and with the observed pattern, most notably in the free atmosphere. An anticyclonic circulation is found east of the warm SST core together with a tropospheric warming in the three models, while in the lower stratosphere cold anomalies are shown only in CNRM and EC-EARTH but a relative cooling is present in CMCC (Fig. 11). Note that the ture $(\mathrm{K} ; \mathbf{c}-\mathbf{h})$ at different levels with solid color areas representing signals which are statistically significant at $90 \%$ confidence level with a Cramer's test. The contours are for NCEP mean sea level pressure (from -5.00 to $5.00 \mathrm{hPa}$, contour interval: $0.25 \mathrm{hPa}$; a, b) and geopotential height (from -50 to $50 \mathrm{~m}$, contour interval: $5 \mathrm{~m}$; $\mathbf{c}-\mathbf{h}$ ) at different levels with dashed negative anomalies. Black contours represent regions with a signal statistically significant at $90 \%$ confidence level with a Cramer's test

atmospheric response to $\mathrm{PDO}_{-}$is indeed consistent with the linear response to a warm thermal forcing in the extratropics as described by Hoskins and Karoly (1981); CMCC even shows some baroclinicity in the lower troposphere.

Turbulent heat fluxes (THF) play a fundamental role in air-sea interaction, particularly at extratropical latitudes (e.g. see Frankignoul 1985 for review). To further understand the differences between the atmospheric response to $\mathrm{PDO}_{+}$ and $\mathrm{PDO}_{-}$, ensemble-mean THF anomalies are diagnosed (Fig. 12), as the sum of the latent and sensible heat fluxes (positive upwards). Note that both components act in tandem although dominated in amplitude by the latent heat flux (not shown). Under $\mathrm{PDO}_{+}$conditions (Fig. 12a, c, e), the PDO forcing leads to a marked model diversity of the heat uptake (negative TFH), with EC-EARTH centred around the Date Line (Fig. 12e), CMCC located westward (Fig. 12a), and CNRM divided eastward and over the westernmost part of the basin (Fig. 12c). Conversely, under PDO_ conditions 

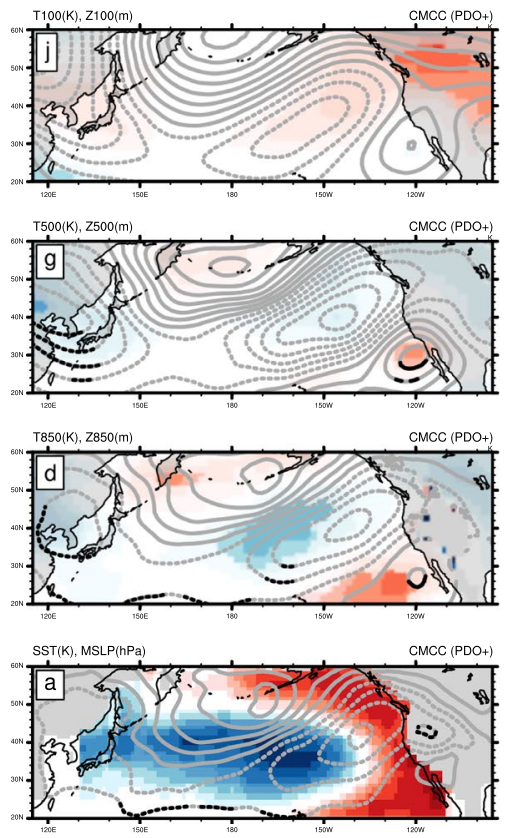
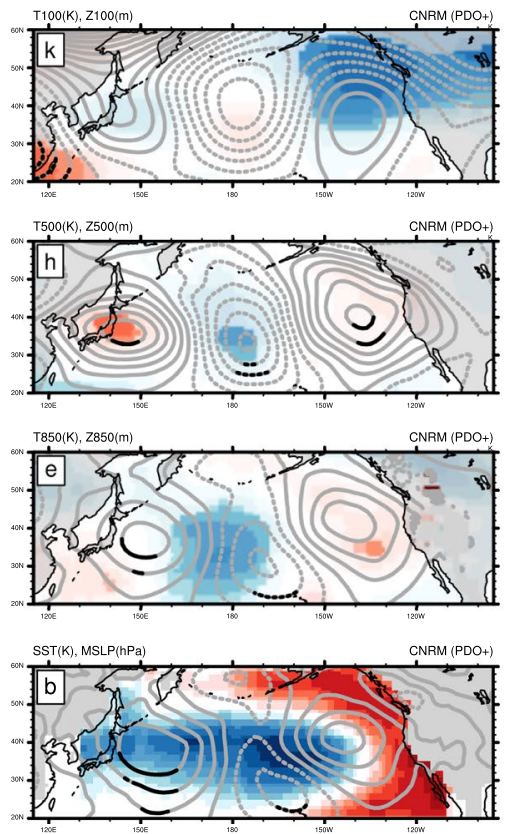
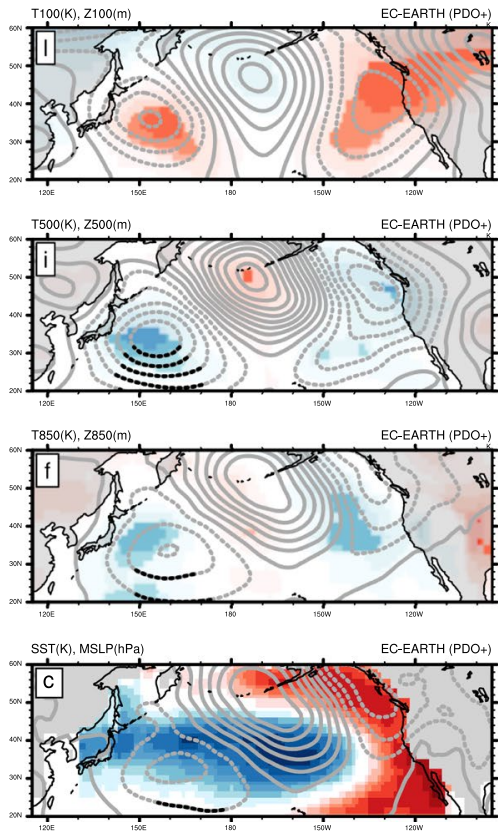

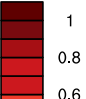

0.6

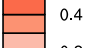

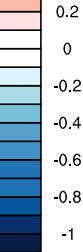

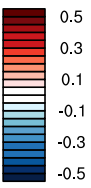

Fig. 10 Late winter (JFM) $\mathrm{PDO}_{+}$response $\left(\mathrm{PDO}_{+}-\mathrm{CTL}\right)$ at surface $(\mathbf{a}-\mathbf{c})$ and at different levels in the troposphere: $850 \mathrm{hPa}(\mathbf{d}-\mathbf{f})$, $500 \mathrm{hPa}(\mathbf{g}-\mathbf{i})$, and $100 \mathrm{hPa}(\mathbf{j}-\mathbf{l})$, as in Fig. 2 of Luo et al. (2020). Left column: results from CMCC model; middle column: results from CNRM model; right column: results from EC-EARTH model. The shading is for sea surface temperature $(\mathrm{K} ; \mathbf{a}-\mathbf{c})$ and air temperature $(\mathrm{K} ; \mathbf{d}-\mathbf{l})$ at different levels with solid color areas representing

(Fig. 12b, d, f), the PDO forcing is associated with a robust, and consistent across models, heat release (positive THF) over the Kuroshio-Oyashio Extension along $40^{\circ} \mathrm{N}$. This different behaviour is likely related to the model sensitivity of how the PDO phases distinctly modify the meridional gradient between middle and subpolar latitudes: namely $\mathrm{PDO}_{+}$ ( $\mathrm{PDO}_{-}$) reduces (enhances) the climatological meridional gradient, whereby it dampens (strengthens) the effective forcing of the atmosphere. These features suggest a consistent interpretation of the results obtained so far, including the coherent influence of $\mathrm{PDO}_{-}$, as compared to $\mathrm{PDO}_{+}$, on the atmospheric background state (Fig. 3), as well as why all the three models simulate a stronger and more linear response to PDO_ (cf. Figs. 10, 11). Furthermore, the different shapes of the PDO response allow to provide a framework for the contrasting modulation patterns commented in Sect. 3. As $\mathrm{PDO}_{-}$represents a more effective forcing, its influence on the atmospheric background state is more pronounced leading to a similar modification of El Niño fingerprint in the multi-model ensemble. Hence, in the following we will investigate the impact of the PDO on the mechanisms responsible of El Niño teleconnection, focusing our analysis on the role of PDO_.

As introduced in Sect. 1, a suitable candidate for the tropospheric pathway of the El Niño-NAE teleconnection signals which are statistically significant at $90 \%$ confidence level with a Student's $t$ test. The contours are for mean sea level pressure (from -5.00 to $5.00 \mathrm{hPa}$, contour interval: $0.25 \mathrm{hPa}$; a-c) and geopotential height (from -20 to $30 \mathrm{~m}$, contour interval: $2 \mathrm{~m}$; d-l) at different levels with dashed negative anomalies. Black contours represent regions with a signal statistically significant at $90 \%$ confidence level with a Student's t test

involves the propagation of planetary Rossby waves crossing the North Pacific-American region (e.g. GarcíaSerrano et al. 2011; Mezzina et al. 2020), analyzed in depth using the MEDSCOPE multi-model by Mezzina et al. (2021). As shown in Sect. 3, PDO_conditions lead to a weakening of the $200 \mathrm{hPa}$ zonal flow in the North Pacific, which appears stronger in CNRM (Fig. 3e) and EC-EARTH (Fig. 3b) and less pronounced in CMCC (Fig. 3e), consistent with the associated circulation anomalies (Fig. 11). Despite their limited amplitude, these anomalies are localized on a crucial sector for the tropical-extratropical interaction: the exit region of the North Pacific jet. Changes in the mean flow are known to influence and guide the propagation of Rossby waves (Hoskins and Karoly 1981; Branstator 1983; Karoly 1983). In the following, two diagnostics are employed to link the impact of PDO_ on the background state to the reported modulation of El Niño teleconnection: the stationary wavenumber $\left(\mathrm{K}_{\mathrm{s}}\right)$ and the wave activity flux (WAF).

Hoskins and Ambrizzi (1993) derived a diagnostic to identify preferred regions for propagation, i.e., the stationary wavenumber $\mathrm{K}_{\mathrm{s}}$ : 

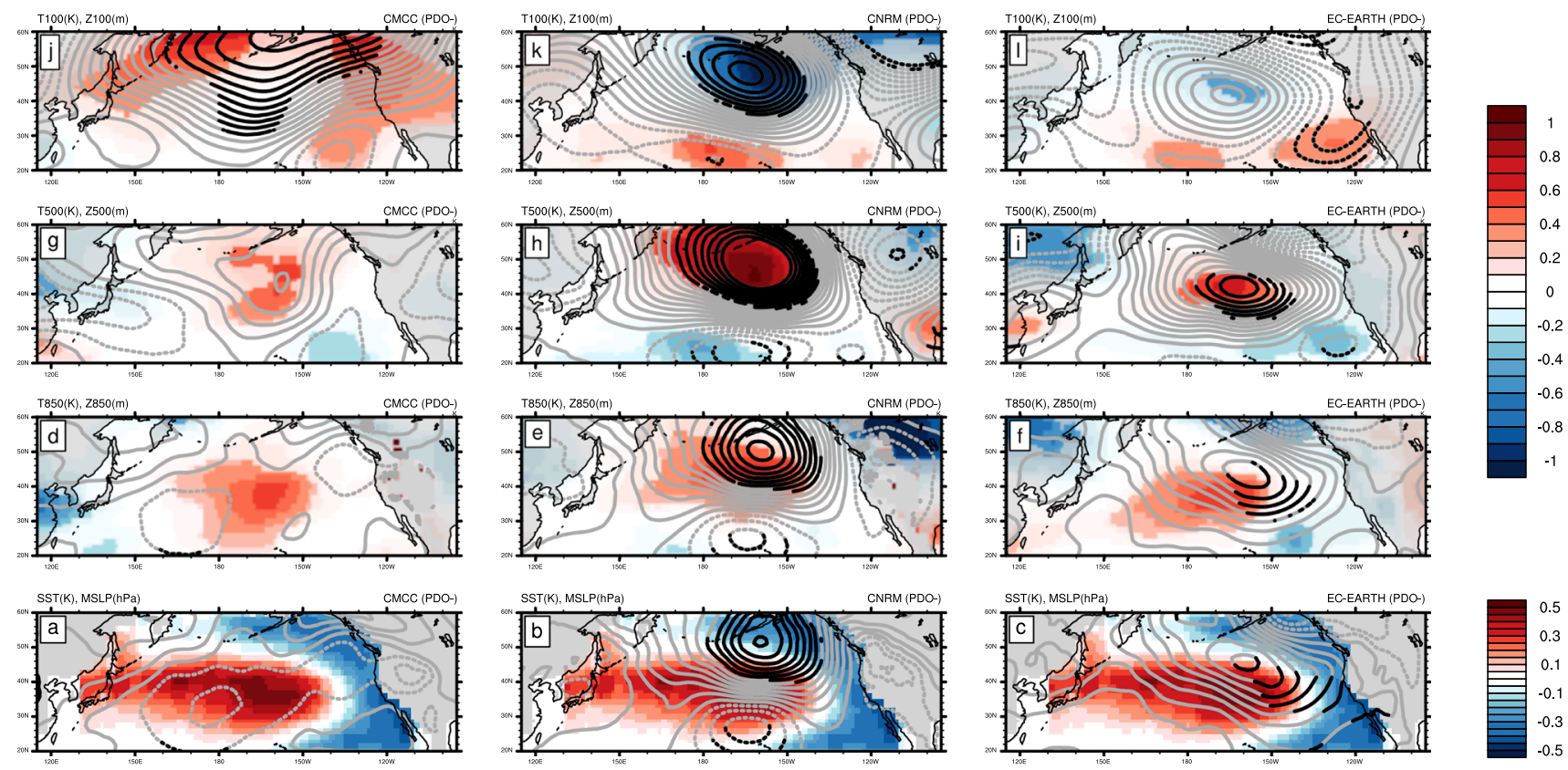

Fig. 11 Late winter (JFM) PDO_ response (PDO_CTL) at surface (ac) and at different levels in the troposphere: $850 \mathrm{hPa}(\mathbf{d}-\mathbf{f}), 500 \mathrm{hPa}$ $(\mathbf{g}-\mathbf{i})$, and $100 \mathrm{hPa}(\mathbf{j}-\mathbf{l})$, as in Fig. 2 of Luo et al. (2020). Left column: results from CMCC model; middle column: results from CNRM model; right column: results from EC-EARTH model. The shading is for sea surface temperature $(\mathrm{K} ; \mathbf{a}-\mathbf{c})$ and air temperature $(\mathrm{K} ; \mathbf{d}-\mathbf{l})$ at different levels with solid color areas representing signals

$K_{s}=\sqrt{\frac{\beta_{M}}{U_{M}}}$ with

$\beta_{M}=\frac{2 \Omega}{a} \cos ^{2} \phi-\frac{\partial}{\partial y} \frac{1}{\cos ^{2} \phi} \frac{\partial}{\partial y}\left(U_{M} \cos ^{2} \phi\right)$,

$\cos \alpha=\frac{k}{K_{S}}=k \sqrt{\frac{U_{M}}{\beta_{M}}}$.

Here $\Omega$ is the Earth's rotation rate, $a$ is the Earth's radius, and $\phi$ is the latitude. $\beta_{M}$ represents the meridional gradient of absolute vorticity, expressed as the sum of planetary and relative vorticity, while $U_{M}$ is the zonal mean-flow on the Mercator projection (Hoskins and Karoly 1981). For stationary waves, $\alpha$ is the angle of the wave energy propagation with the eastward direction; $k$ is the zonal wavenumber. Hoskins and Ambrizzi (1993) showed that Rossby waves tend to be refracted toward latitudes with higher values of $\mathrm{K}_{\mathrm{s}}$. In this sense, the stationary wavenumber is usually adopted as a refractive index for Rossby waves (e.g. Dawson et al. 2011; Schneider et al. 2009). As noted by Dawson et al. (2011), $\mathrm{K}_{\mathrm{s}}$ is highly sensitive to small differences in the background state, hence the observed PDO_-induced changes in the $200 \mathrm{hPa}$ mean flow, even if limited in amplitude, should be which are statistically significant at $90 \%$ confidence level with a Student's $t$ test. The contours are for mean sea level pressure (from -5.00 to $5.00 \mathrm{hPa}$, contour interval: $0.25 \mathrm{hPa}$; $\mathbf{a}-\mathbf{c}$ ) and geopotential height (from-20 to $30 \mathrm{~m}$, contour interval: $2 \mathrm{~m}$; d-l) at different levels with dashed negative anomalies. Black contours represent regions with a signal statistically significant at $90 \%$ confidence level with a Student's t test

expected to have a significant impact on the Rossby wave propagation path. This potential alteration could in turn modify the effectiveness of the teleconnection dynamics, and hence may explain the potential modulation of the El Niño signal over the NAE sector.

In order to evaluate how the propagation of the El Niñoforced wave-train is affected by the PDO-induced changes in the mean-flow, the wave activity flux (Plumb 1985) has been considered. Under the Wentzel-Kramers-Brillouin (WKB) approximation, WAF is parallel to the group velocity and phase-independent.

$\left(\begin{array}{c}F_{x} \\ F_{y}\end{array}\right)=p \cos \phi\left(\begin{array}{c}\frac{1}{2 a^{2} \cos ^{2} \phi}\left[\left(\frac{\partial \psi^{*}}{\partial \lambda}\right)^{2}-\psi^{*} \frac{\partial^{2} \psi^{*}}{\partial \lambda^{2}}\right] \\ \frac{1}{2 a^{2} \cos ^{2} \phi}\left[\frac{\partial \psi^{*}}{\partial \lambda} \frac{\partial \psi^{*}}{\partial \phi}-\psi^{*} \frac{\partial^{2} \psi^{*}}{\partial \lambda \partial \phi}\right]\end{array}\right)$.

Here $\psi^{*}$ is the zonally asymmetric part of the geostrophic streamfunction, $\phi$ and $\lambda$ indicate respectively latitude and longitude, $p$ is the pressure level normalized by $1000 \mathrm{hPa}$, and $a$ the Earth's radius.

Figure 13 shows the WAF and the associated $200 \mathrm{hPa}$ geostrophic streamfunction response to El Niño under climatological mid-latitude conditions (EN-CTL; Fig. 13a, c, e) together with the WAF modulation under 

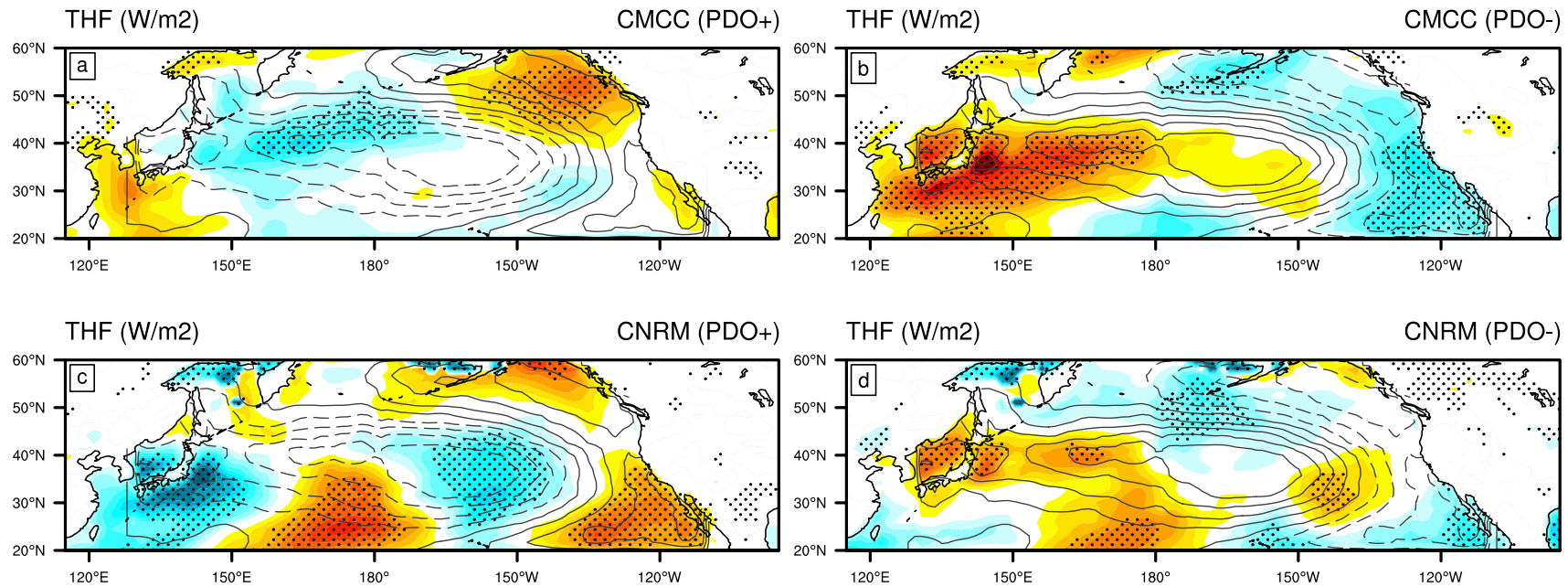

THF $(\mathrm{W} / \mathrm{m} 2)$ EC-EARTH (PDO+) THF (W/m2)

EC-EARTH (PDO-)
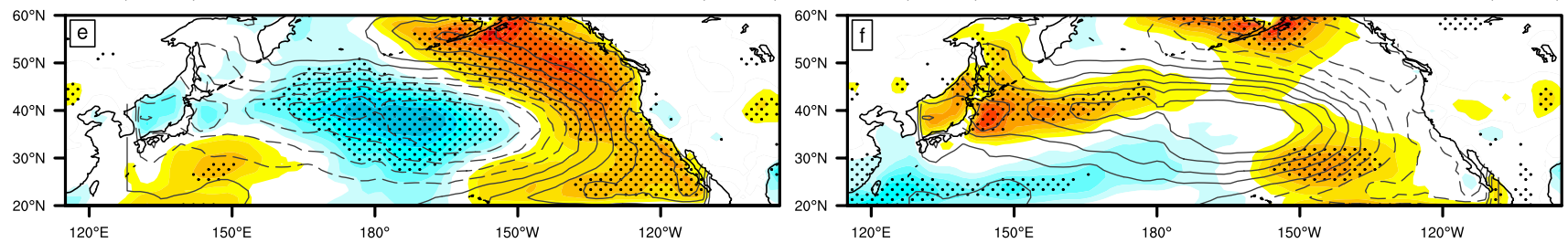

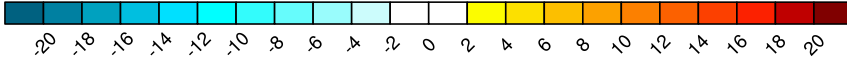

Fig. 12 Late winter (JFM) turbulent heat flux $\left(\mathrm{W} / \mathrm{m}^{2}\right)$ response to $\mathrm{PDO}_{+}$(left column) and PDO_ (right column) over the Pacific sector. The contours with dashed negative values represent the PDO SST forcing (from -0.5 to $0.5 \mathrm{~K}$, contour interval: $0.1 \mathrm{~K}$ ). Top row: results

$\mathrm{PDO}_{-}$conditions (i.e. (EN/ PDO_- PDO_)-(EN-CTL); Fig. 13b,d,f) superimposed on the anomalies of $\mathrm{K}_{\mathrm{s}}$ induced by PDO_ (PDO_-CTL). The El Niño teleconnection is characterized by the well-known wave-train arching northeastward over the North Pacific-American region, whose vertical tilt with height projects on the canonical dipolar pattern over the North Atlantic-European region (Fig. 5; Mezzina et al. 2020, 2021). The changes in $K_{s}$, induced by PDO_ (Fig. 13b, d, f), reveal an enhanced waveguide over the eastern North Pacific, consistent with the weakening of the jet. This increase in $\mathrm{K}_{\mathrm{s}}$ is associated with a more poleward propagation of the wave energy, i.e. larger values of $\alpha$ (smaller $\cos \alpha$ for a given wavenumber $k$ ). The role of the modified background flow is confirmed by the WAF modulation, exhibiting an increased divergence and more northeastward propagation over the Aleutian Island region, spatially coherent with the positive $\mathrm{K}_{\mathrm{s}}$ anomalies. The enhanced wave path over the North Pacific due to PDO_ reinforces the El Niño wave-train across the North Pacific-American sector, which contributes to the development of the signal over the North Atlantic-European sector. These results are overall in agreement with López-Parages et al. (2015, 2016b). The from CMCC model; middle row: results from CNRM model; bottom row: results from EC-EARTH model. The dotted regions are statistically significant at $90 \%$ confidence level with a Student's t test

same analysis has been carried out also for $\mathrm{PDO}_{+}$conditions (not shown) and, as expected, the results are largely modeldependent, inconsistent and not statistically significant.

\section{Discussion and conclusions}

In this work, the impact of low-frequency SST variability over the extratropical Pacific on the El Niño teleconnection has been explored. It is well-known that ENSO represents the primary source of seasonal predictability at the global scale (e.g. Manzanas et al. 2014). Despite the strong variability characterizing the mid-latitude atmosphere, the emergence of a systematic impact of El Niño over the NAE sector, and hence over the Euro-Mediterranean area, is expected to increase the regional climate predictability (e.g. Frías et al. 2010). At the same time, the potential nonstationary nature of the ENSO signal may play a role in this framework (e.g. O'Reilly 2018), likely altering the seasonal forecast skill at both global and regional scale (e.g. O'Reilly et al. 2017; Weisheimer et al. 2017). 


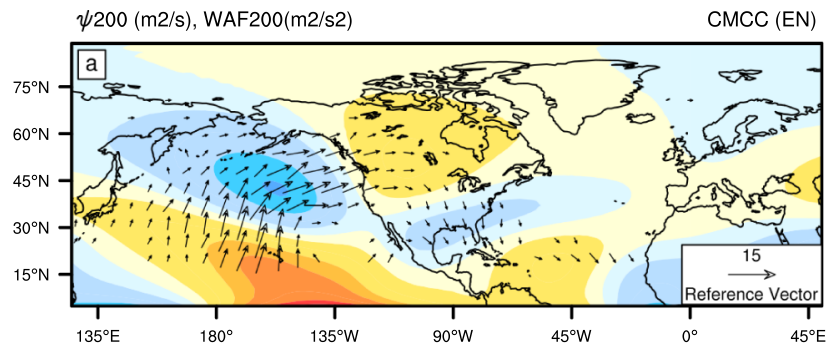

$\psi 200(\mathrm{~m} 2 / \mathrm{s})$, WAF200(m2/s2)

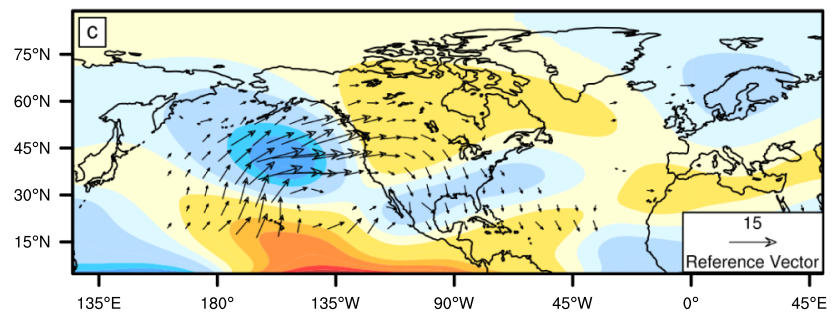

$\psi 200$ (m2/s), WAF200(m2/s2)

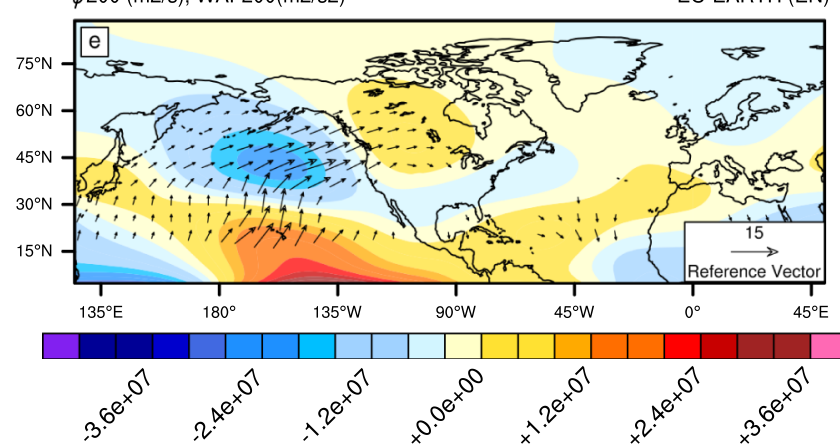

Fig. 13 Late winter (JFM) El Niño teleconnection at $200 \mathrm{hPa}$ and its modulation due to PDO-conditions. On the left column: wave activity flux (arrows; $\mathrm{m}^{2} \mathrm{~s}^{-2}$ ) and $200 \mathrm{hPa}$ streamfunction (shading; $\mathrm{m}^{2}$ $\mathrm{s}^{-1}$ ) for El Niño (EN-CTL). The wave activity flux is shown between $20^{\circ} \mathrm{N}$ and $70^{\circ} \mathrm{N}$, and only values greater than $1.5 \mathrm{~m}^{2} \mathrm{~s}^{-2}$ are displayed. On the right column: WAF modulation ((EN/PDO_-PDO_) (EN-CTL); arrows, $\mathrm{m}^{2} \mathrm{~s}^{-2}$ ) superimposed on the $\mathrm{PDO}_{-}$stationary

For a deeper understanding on possible processes driving atmospheric circulation variability in the Euro-Mediterranean region, a set of idealized sensitivity experiments has been performed, tailored at investigating the potential impact of the PDO phases on the El Niño teleconnection to the Euro-Atlantic sector. The analysis is focused on late winter (JFM), when the El Niño signal is expected to be detectable (e.g. Brönnimann 2007). A first conclusion that can be drawn from the study is that the presence of the PDO (with realistic magnitude) does not substantially modify the El Niño teleconnection itself, but rather modulates its amplitude. It is concluded that the potential modulation of the PDO would be of second order as compared to the El Niño signal.

The multi-model ensemble offers a coherent picture for the potential modulation under negative PDO conditions

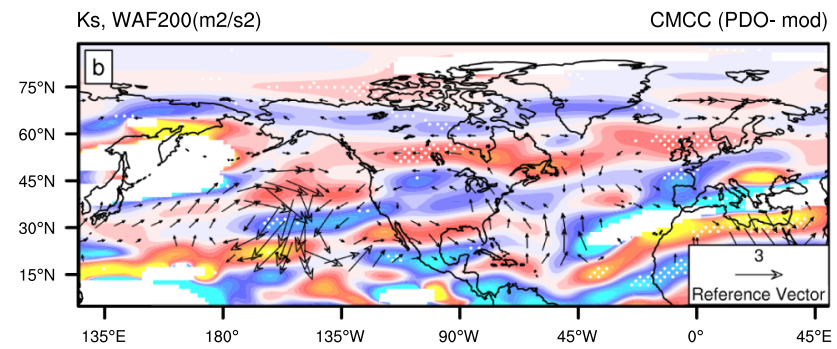

$\mathrm{Ks}, \mathrm{WAF} 200(\mathrm{~m} 2 / \mathrm{s} 2)$

CNRM (PDO- mod)

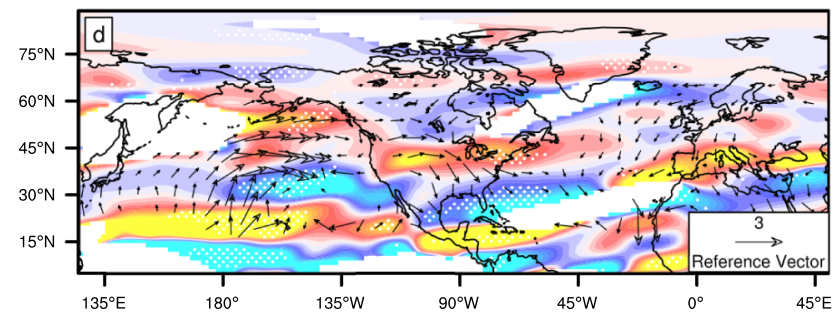

Ks, WAF200(m2/s2)

EC-EARTH (PDO- mod)

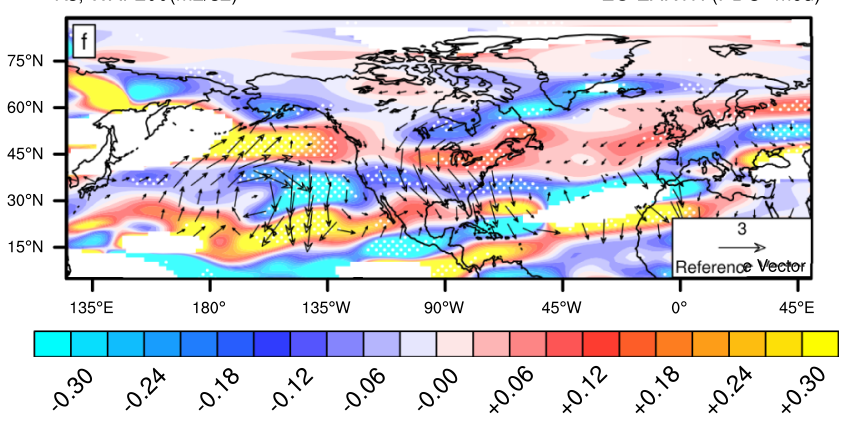

wavenumber (shading; dotted regions are statistically significant with a $90 \%$ confidence level with a Student's t test). The wave activity flux is shown between $20^{\circ} \mathrm{N}$ and $70^{\circ} \mathrm{N}$, and only values greater than $0.3 \mathrm{~m}^{2} \mathrm{~s}^{-2}$ are displayed. Top row: results from CMCC model; middle row: results from CNRM model; bottom row: results from ECEARTH model

(PDO_), with an amplification of the (canonical) surface dipolar pattern over NAE leading to an enhanced precipitation signature over the western part of the Euro-Mediterranean area, as well as to a more pronounced cooling over Scandinavia. On the contrary, positive PDO conditions $\left(\mathrm{PDO}_{+}\right)$provide contrasting patterns. It should be noticed that investigating the mechanisms driving the direct atmospheric response to the PDO forcing is beyond the scope of this work. However, the evaluation of the multimodel signals to the common PDO forcing has allowed to put the modulation results into context. Indeed, while for PDO_ the three models show a similar response especially in the free atmosphere, for $\mathrm{PDO}_{+}$the response is generally weaker and noisier. This asymmetric behavior has been explained in terms of different effective atmospheric forcing, as the air-sea coupling is by construction not included. 
PDO_ $\left(\mathrm{PDO}_{+}\right)$amplifies (reduces) the climatological meridional gradient between middle and high latitudes, which appears to lead to a coherent model sensitivity (enhanced model diversity) in the atmospheric response. Therefore, the analysis of the mechanisms behind the potential modulation of the El Niño teleconnection has been focused on the negative PDO phase.

PDO_ has been found to weaken the North Pacific jet. An altered upper-level mean flow modifies the pathway for the El Niño-induced Rossby waves, as confirmed by the stationary wavenumber diagnostic. In particular, PDO_ seems to enhance the waveguide in the North Pacific, favoring a more poleward propagation of planetary waves across the North Pacific-American sector and in turn an amplification of the El Niño-NAE teleconnection. Our findings support and complement the results by López-Parages et al. (2015) and López-Parages et al. (2016b) by employing a targeted atmosphere-only setup with a multi-model ensemble. In their work, the potential modulating role of low-frequency North Pacific SST variability was identified through an indirect, statistical analysis of strong and weak ENSO signals in observations and long-term coupled runs. Our idealized framework has allowed to diagnose the same dynamics and to unambiguously attribute the changes to the specific forcing applied.

It should be stressed that low frequency variability in the North Pacific jet could be affected also by external forcing (Matsumura et al. 2019) as well as by internal oceanic variability in other basins, e.g. the Atlantic Multidecadal Oscillation (AMO; Knight et al. 2005) which has been shown to impact the atmospheric circulation in the extratropical North Pacific (e.g. Zhang and Delworth 2007; RuprichRobert et al. 2017; Ruggieri et al. 2021). These changes in the North Pacific jet may in turn lead to a modulation of the El Niño teleconnection in mid-latitudes similar to the mechanism proposed in this work.

Here some indication of a changing late winter El NiñoNAE teleconnection is found, fostering a potential amplification of the wet-dry dipole over the Euro-Mediterranean domain under negative PDO conditions. Although this modulation is found to be weak, it is interesting to consider that it might imply some conditional predictability for regional climate in seasonal-to-decadal forecasting, hence it could be further explored.

Some notes on the strength and limitation of the experimental set-up follow. Although idealized in form, the El Niño forcing was realistic in magnitude and comparable to strong events in the observational record (e.g. Hardiman et al. 2019; see Sect. 2), as in recent studies (e.g. JiménezEsteve and Domeisen 2019; Trascasa-Castro et al. 2019). However, and in common with these recent studies, we have not explored the full diversity of ENSO (Capotondi et al. 2015; Timmermann et al. 2018). Although in principle the mechanism for PDO modulation described here should be independent of the ENSO-related planetary wave phase, potential asymmetries and non-linearities could lead to different effects. Future research could be devoted to evaluating the PDO impact upon the seasonality of the El Niño-NAE teleconnection (e.g. Ayarzagüena et al. 2018; King et al. 2018) and to assess the sensitivity of the PDO influence to the different ENSO phases (El Niño vs La Niña; e.g. Mezzina et al. 2021) and flavors (Eastern Pacific vs Central Pacific; e.g. Feng et al. 2017), or to perform partiallycoupled experiments in order to analyze the effect of air-sea interaction on the amplitude of the signals (e.g. López-Parages et al. 2016a).

Acknowledgements This work has been performed in the framework of the MEDSCOPE (MEDiterranean Services Chain based on climate PrEdictions) ERA4CS project (grant agreement no. 690462) funded by the European Union. J.G.-S. was supported by the "Ramón y Cajal" programme (RYC-2016-21181). F.M.P. was partially supported by the Spanish DANAE (CGL2015-68342-R) and GRAVITOCAST (ERC2018-092835) projects. We greatly thank the two anonymous reviewers for the insightful and constructive comments and suggestions.

Open Access This article is licensed under a Creative Commons Attribution 4.0 International License, which permits use, sharing, adaptation, distribution and reproduction in any medium or format, as long as you give appropriate credit to the original author(s) and the source, provide a link to the Creative Commons licence, and indicate if changes were made. The images or other third party material in this article are included in the article's Creative Commons licence, unless indicated otherwise in a credit line to the material. If material is not included in the article's Creative Commons licence and your intended use is not permitted by statutory regulation or exceeds the permitted use, you will need to obtain permission directly from the copyright holder. To view a copy of this licence, visit http://creativecommons.org/licenses/by/4.0/.

\section{References}

Alexander MA, Bladé I, Newman M, Lanzante JR, Lau NC, Scott JD (2002) The atmospheric bridge: the influence of ENSO teleconnections on air-sea interaction over the global oceans. J Clim 15(16):2205-2231. https://doi.org/10.1175/1520-0442(2002) 015\%3c2205:TABTIO\%3e2.0.CO;2

Ayarzagüena B, Ineson S, Dunstone NJ, Baldwin MP, Scaife AA (2018) Intraseasonal effects of El Niño-Southern oscillation on North Atlantic Climate. J Clim 31(21):8861-8873. https://doi.org/ 10.1175/JCLI-D-18-0097.1

Bladé I, Newman M, Alexander A, Scott JD (2008) The late fall extratropical response to ENSO: sensitivity to coupling and convection in the tropical West Pacific. J Clim 21(23):6101-6118. https://doi. org/10.1175/2008JCLI1612.1

Branstator G (1983) Horizontal energy propagation in a barotropic atmosphere with meridional and zonal structure. J Atmos Sci 40(7):1661-1671. https://doi.org/10.1175/1520-0469(1983)040\% 3c1689:HEPIAB\%3e2.0.CO;2

Brönnimann S (2007) Impact of El Niño-Southern Oscillation on European Climate. Rev Geophys. https://doi.org/10.1029/2006R G000199 
Brönnimann S, Xoplaki E, Casty C, Pauling A, Luterbacher J (2007) ENSO influence on Europe during the last centuries. Clim Dyn 28(2-3):181-197. https://doi.org/10.1007/s00382-006-0175-z

Cagnazzo C, Manzini E (2009) Impact of the stratosphere on the winter tropospheric teleconnections between ENSO and the North Atlantic and European region. J Clim 22(1223-1238):2009. https://doi. org/10.1175/2008JCLI2549.1

Capotondi A, Wittenberg AT, Newman M, Di Lorenzo E, Yu J, Braconnot P, Cole J, Dewitte B, Giese B, Guilyardi E, Jin F, Karnauskas K, Kirtman B, Lee T, Schneider N, Xue Y, Yeh S (2015) Understanding ENSO Diversity. Bull Am Meteor Soc 96(6):921-938. https://doi.org/10.1175/BAMS-D-13-00117.1

Davini P, Von Hardenberg J, Corti S, Christensen HM, Juricke S, Subramanian A, Watson PAG, Weisheimer A, Palmer TN (2017) Climate SPHINX: Evaluating the impact of resolution and stochastic physics parameterisations in climate simulations. Geosci Model Dev. https://doi.org/10.5194/gmd-2016-115

Dawson A, Matthews AJ, Stevens DP (2011) Rossby wave dynamics of the North Pacific extra-tropical response to El Niño: importance of the basic state in coupled GCMs. Clim Dyn 37(1-2):391-405. https://doi.org/10.1007/s00382-010-0854-7

Deser C, Simpson IR, McKinnon KA, Phillips AS (2017) The Northern Hemisphere Extratropical Atmospheric Circulation Response to ENSO: How Well Do We Know It and How Do We Evaluate Models Accordingly? J Clim 30(13):5059-5082. https://doi.org/ 10.1175/JCLI-D-16-0844.1

DeWeaver E, Nigam S (2000) Do stationary waves drive the zonalmean jet anomalies of the Northern Winter? J Clim 13(13):2160 2176. https://doi.org/10.1175/1520-0442(2000)013\%3c2160: DSWDTZ\%3e2.0.CO;2

Ding S, Chen W, Feng J, Graf HF (2017) Combined Impacts of PDO and the two types of La Niña on climate anomalies in Europe. $\mathrm{J}$ Clim 30:3253-3278. https://doi.org/10.1175/JCLI-D-16-0376.1

Doblas-Reyes FJ, García-Serrano J, Lienert F, Biescas AP, Rodrigues LRL (2013) Seasonal climate predictability and forecasting: status and prospects. Wiley Interdiscip Rev Clim Change 4(4):245-268. https://doi.org/10.1002/wcc.217

Domeisen DI, Garfinkel CI, Butler AH (2019) The teleconnection of El Niño Southern Oscillation to the stratosphere. Rev Geophys 57:5-47. https://doi.org/10.1029/2018RG000596

Dong B, Dai A, Vuille M, Timm OE (2018) Asymmetric modulation of ENSO teleconnections by the interdecadal Pacific Oscillation. J Clim 31:7337-7361. https://doi.org/10.1175/JCLI-D-17-0663.1

Drouard M, Cassou C (2019) A modeling- and process-oriented study to investigate the projected change of ENSO-forced wintertime teleconnectivity in a warmer world. J Clim 32:8047-8068. https:// doi.org/10.1175/JCLI-D-18-0803.1

Drouard M, Riviére G, Arbogast P (2015) The link between the North Pacific climate variability and the North Atlantic Oscillation via Downstream propagation of synoptic waves. J Clim 28(10):39573976. https://doi.org/10.1175/JCLI-D-14-00552.1

Dunstone N, Smith D, Scaife AA, Hermanson L, Eade R, Robinson N, Andrews M, Knight J (2016) Skilful predictions of the winter North Atlantic Oscillation one year ahead. Nat Geosci 9(11):809_ 814. https://doi.org/10.1038/ngeo2824

Feng J, Chen W, Li Y (2017) Asymmetry of the winter extra-tropical teleconnections in the Northern Hemisphere associated with two types of ENSO. Clim Dyn 48:2135-2151. https://doi.org/10.1007/ s00382-016-3196-2

Fraedrich K, Müller K (1992) Climate anomalies in Europe associated with ENSO extremes. Int J Climatol 12:25-31. https://doi.org/10. 1002/joc.3370120104

Frankignoul C (1985) Sea surface temperature anomalies, planetary waves, and air-sea feedback in the middle latitudes. Rev Geophys 23(4):357-390. https://doi.org/10.1029/RG023i004p00357
Frías MD, Herrera S, Cofiño AS, Gutiérrez JM (2010) Assessing the skill of precipitation and temperature seasonal forecasts in Spain: windows of opportunity related to ENSO events. J Clim 23(2):209-220. https://doi.org/10.1175/2009JCLI2824.1

García-Serrano J, Rodríguez-Fonseca B, Bladé I, Zurita-Gotor P, de la Cámara A (2011) Rotational atmospheric circulation during North Atlantic-European winter: the influence of ENSO. Clim Dyn 37:1727-1743. https://doi.org/10.1007/s00382-010-0968-y

Gershunov A, Barnett TP (1998) Interdecadal modulation of ENSO teleconnections. Bull Am Meteor Soc 79:2715-2726. https://doi. org/10.1175/1520-0477(1998)079\%3c2715:IMOET\%3e2.0.CO;2

Gouirand I, Moron V (2003) Variability of the impact of El Niñosouthern oscillation on sea-level pressure anomalies over the North Atlantic in January to March (1874-1996). Int J Climatol 23(13):1549-1566. https://doi.org/10.1002/joc.963

Graf HF, Zanchettin D (2012) Central Pacific El Niño, the "subtropical bridge", and Eurasian climate. J Geophys Res Atmos. https://doi.org/10.1029/2011JD016493

Haarsma R, Acosta M, Bakhshi R, Bretonnière PA, Caron LP, Castrillo M, Corti S, Davini P, Exarchou E, Fabiano F, Fladrich U, Fuentes Franco R, García-Serrano J, von Hardenberg J, Koenigk T, Levine X, Meccia VL, van Noije T, van den Oord G, Palmeiro FM, Rodrigo M, Ruprich-Robert Y, Le Sager P, Tourigny E, Wang S, van Weele M, Wyser K (2020) HighResMIP versions of EC-Earth: EC-Earth3P and EC-Earth3PHR-description, model computational performance and basic validation. Geosci Model Dev 13(8):3507-3527. https://doi.org/ 10.5194/gmd-13-3507-2020

Ham YG, Sung MK, An SI, Schubert SD, Kug JS (2014) Role of tropical Atlantic SST variability as a modulator of El Niño teleconnections. Asia Pac J Atmos Sci 50(3):247-261. https://doi.org/10. 1007/s13143-014-0013-x

Hardiman SC, Dunstone NJ, Scaife AA, Smith DM, Ineson S, Lim J, Fereday D (2019) The impact of strong El Niño and La Niña events on the North Atlantic. Geophys Res Lett 46(5):2874-2883. https://doi.org/10.1029/2018GL081776

Honda M, Nakamura H, Ukita J, Kousaka I, Takeuchi K (2001) Interannual see-saw between the Aleutian and Icelandic lows. Part I: seasonal dependence and life cycle. J Clim 14:1029-1042. https://doi. org/10.1175/1520-0442(2001)014\%3c1029:ISBTAA\%3e2.0.CO;2

Horel JD, Wallace JM (1981) Planetary-scale atmospheric phenomena associated with the Southern Oscillation. Mon Weather Rev 109(4):813-829. https://doi.org/10.1175/1520-0493(1981)109\% 3c0813:PSAPAW\%3e2.0.CO;2

Hoskins BJ, Ambrizzi T (1993) Rossby wave propagation on a realistic longitudinally varying flow. J Atmos Sci 50(12):16611671. https://doi.org/10.1175/1520-0469(1993)050\%3c1661: RWPOAR\%3e2.0.CO;2

Hoskins BJ, Karoly DJ (1981) The steady linear response of a spherical atmosphere to thermal and orographic forcing. J Atmos Sci 38(6):1179-1196. https://doi.org/10.1175/1520-0469(1981)038\% 3c1179:TSLROA\%3e2.0.CO;2

Ineson S, Scaife AA (2009) The role of the stratosphere in the European climate response to El Niño. Nat Geosci 2(1):32-36. https:// doi.org/10.1038/ngeo381

Jiménez-Esteve B, Domeisen DIV (2018) The Tropospheric pathway of ENSO- North Atlantic teleconnection. J Clim 31(11):4563-4584. https://doi.org/10.1175/JCLI-D-17-0716.1

Jiménez-Esteve B, Domeisen DIV (2019) Nonlinearity in the North Pacific atmospheric response to a linear ENSO forcing. Geophys Res Lett 46(4):2271-2281. https://doi.org/10.1029/2018GL0812 26

Kalnay E, Kanamitsu M, Kistler R, Collins W, Deaven D, Gandin L, Iredell M, Saha S, White G, Woollen J, Zhu Y, Chelliah M, Ebisuzaki W, Higgins W, Janowiak J, Mo KC, Ropelewski C, Wang J, Leetmaa A, Reynolds R, Jenne R, Joseph D (1996) The 
NCEP/NCAR 40-year reanalysis project. Bull Am Meteor Soc 77(3):437-472. https://doi.org/10.1175/1520-0477(1996)077\% 3c0437:TNYRP\%3e2.0.CO;2

Karoly DJ (1983) Rossby wave propagation in a barotropic atmosphere. Dyn Atmos Oceans 7:111-125. https://doi.org/10.1016/ 0377-0265(83)90013-1

King MP, Herceg-Bulić I, Bladé I, García-Serrano J, Keenlyside N, Kucharski F, Li C, Sobolowski S (2018) Importance of Late Fall ENSO teleconnection in the Euro-Atlantic sector. Bull Am Meteor Soc 99(7):1337-1343. https://doi.org/10.1175/ BAMS-D-17-0020.1

Knight JR, Allan RJ, Folland CK, Vellinga M, Mann ME (2005) A signature of persistent natural thermohaline circulation cycles in observed climate. Geophys Res Lett 32:L20708. https://doi.org/ 10.1029/2005GL024233

Kushnir Y, Robinson WA, Bladé I, Hall NMJ, Peng S, Sutton R (2002) Atmospheric GCM response to extratropical SST anomalies: synthesis and evaluation*. J Clim 15(16):2233-2256. https://doi.org/ 10.1175/1520-0442(2002)015\%3c2233:AGRTES\%3e2.0.CO;2

Latif M, Barnett TP (1994) Causes of decadal climate variability over the North Pacific and North America. Science 266(5185):634 637. https://doi.org/10.1126/science.266.5185.634

Li Y, Lau NC (2012) Impact of ENSO on the atmospheric variability over the North Atlantic in Late Winter-role of transient Eddies. J Clim 25(1):320-342. https://doi.org/10.1175/JCLI-D-11-00037.1

López-Parages J, Rodríguez-Fonseca B (2012) Multidecadal modulation of El Niño influence on the Euro-Mediterranean rainfall. Geophys Res Lett. https://doi.org/10.1029/2011GL050049

López-Parages J, Rodríguez-Fonseca B, Terray L (2015) A mechanism for the multidecadal modulation of ENSO teleconnection with Europe. Clim Dyn 45:867-880. https://doi.org/10.1007/ s00382-014-2319-x

López-Parages J, Rodríguez-Fonseca B, Dommenget D, Frauen C (2016a) ENSO influence on the North Atlantic European climate: a non-linear and non-stationary approach. Clim Dyn 47:20712084. https://doi.org/10.1007/s00382-015-2951-0

López-Parages J, Rodríguez-Fonseca B, Mohino E, Losada T (2016b) Multidecadal modulation of ENSO teleconnection with Europe in Late Winter: analysis of CMIP5 Models. J Clim 29(2):8067-8081. https://doi.org/10.1175/JCLI-D-15-0596.1

Luo H, Zheng F, Keenlyside N, Zhu J (2020) Ocean-atmosphere coupled Pacific Decadal variability simulated by a climate model. Clim Dyn 54:4759-4773. https://doi.org/10.1007/ s00382-020-05248-9

Mantua NJ, Hare SR, Zhang Y, Wallace JM, Francis RC (1997) A Pacific interdecadal climate oscillation with impacts on salmon production. Bull Am Meteor Soc 78(6):1069-1080. https://doi. org/10.1175/1520-0477(1997)078\%3c1069:APICOW\%3e2.0. $\mathrm{CO} ; 2$

Manzanas R, Frías MD, Cofiño AS, Gutiérrez JM (2014) Validation of 40 year multimodel seasonal precipitation forecasts: the role of ENSO on the global skill. J Geophys Res Atmos 119(4):17081719. https://doi.org/10.1002/2013JD020680

Mariotti A, Zeng N, Lau KM (2002) Euro-Mediterranean rainfall and ENSO - a seasonally varying relationship. Geophys Res Lett. https://doi.org/10.1029/2001GL014248

Mariotti A, Ballabrera-Poy J, Zeng N (2005) Tropical influence on Euro-Asian autumn rainfall variability. Clim Dyn 24:511-521. https://doi.org/10.1007/s00382-004-0498-6

Mathieu PP, Sutton RT, Dong B, Collins M (2004) Predictability of Winter Climate over the North Atlantic European Region during ENSO Events. J Clim 17(10):1953-1974. https://doi.org/10.1175/ 1520-0442(2004)017\%3c1953:POWCOT\%3e2.0.CO;2

Matsumura S, Ueki S, Horinouchi T (2019) Contrasting responses of midlatitude jets to the North Pacific and North Atlantic Warming.
Geophys Res Lett 46(7):3973-3981. https://doi.org/10.1029/ 2019GL082550

McCabe GJ, Dettinger MD (1999) Decadal variations in the strength of ENSO teleconnections with precipitation in the western United States. Int J Climatol 19(13):1399-1410. https://doi.org/10.1002/ (SICI) 1097-0088(19991115)19:13\%3c1399::AID-JOC457\% 3e3.0.CO;2-A

McPhaden MJ, Zebiak SE, Glantz MH (2006) ENSO as an integrating concept in earth science. Science 314(5806):1740-1745. https:// doi.org/10.1126/science.1132588

Mezzina B, García-Serrano J, Bladé I, Kucharski F (2020) Dynamics of the ENSO Teleconnection and NAO Variability in the North Atlantic-European Late Winter. J Clim 33(3):907-923. https://doi. org/10.1175/JCLI-D-19-0192.1

Mezzina B, García-Serrano J, Bladé I, Palmeiro FM, Batté L, Ardilouze C, Benassi M, Gualdi S (2021) Multi-model assessment of the late-winter extra-tropical response to El Niño and La Niña. Clim Dyn. https://doi.org/10.1007/s00382-020-05415-y (in press)

Newman M, Compo GP, Alexander MA (2003) ENSO-forced variability of the Pacific Decadal Oscillation. J Clim 16(23):38533857. https://doi.org/10.1175/1520-0442(2003)016\%3c3853: EVOTPD\%3e2.0.CO;2

O'Reilly CH (2018) Interdecadal variability of the ENSO teleconnection to the wintertime North Pacific. Clim Dyn 51(9-10):33333350. https://doi.org/10.1007/s00382-018-4081-y

O'Reilly CH, Heatley J, MacLeod D, Weisheimer A, Palmer TN, Schaller N, Woollings T (2017) Variability in seasonal forecast skill of Northern Hemisphere winters over the twentieth century. Geophys Res Lett 44(11):5729-5738. https://doi.org/10.1002/ 2017GL073736

Park S (2004) Remote ENSO influence on Mediterranean sky conditions during late summer and autumn: evidence for a slowly evolving atmospheric bridge. Q J R Meteorol Soc 130(602):2409-2422. https://doi.org/10.1256/qj.03.62

Plumb R (1985) On the three-dimensional propagation of stationary waves. J Atmos Sci 42(3):217-229. https://doi.org/10.1175/15200469(1985)042\%3c0217:OTTDPO\%3e2.0.CO;2

Rao J, Garfinkel CI, Ren R (2019) Modulation of the Northern Winter Stratospheric El Niño-Southern oscillation teleconnection by the PDO. J Clim 32(18):5761-5783. https://doi.org/10.1175/ JCLI-D-19-0087.1

Rayner A, Parker DE, Horton EB, Folland CK, Alexander LV, Rowell DP, Kent EC, Kaplan A (2003) Global analyses of sea surface temperature, sea ice, and night marine air temperature since the late nineteenth century. J Geophys Res Atmos. https://doi.org/10. 1029/2002JD002670

Rodríguez-Fonseca B, Suárez-Moreno R, Ayarzagüena B, López-Parages J, Gómara I, Villamayor J, Mohino E, Losada T, CastanoTierno A (2016) A review of ENSO influence on the North Atlantic. a non-stationary signal. Atmosphere. https://doi.org/10.3390/ atmos 7070087

Roehrig R, Beau I, Saint-Martin D, Alias A, Decharme B, Guérémy JF, Voldoire A, Abdel-Lathif AY, Bazile E, Belamari S, Blein S, Bouniol D, Bouteloup Y, Cattiaux J, Chauvin F, Chevallier M, Colin J, Douville H, Marquet P, Michou M, Nabat P, Oudar T, Peyrillé P, Piriou JM, Salas y Mélia D, Séférian R, and Sénési S, (2020) The CNRM global atmosphere model ARPEGE-climate 6.3: description and evaluation. J Adv Model Earth Syst. https:// doi.org/10.1029/2020MS002075

Ruggieri P, Bellucci A, Nicolí D, Athanasiadis PJ, Gualdi S, Cassou C, Castruccio F, Danabasoglu G, Davini P, Dunstone N, Eade R, Gastineau G, Harvey B, Hermanson L, Qasmi S, RuprichRobert Y, Sanchez-Gomez E, Smith D, Wild S, Zampieri M (2021) Atlantic multidecadal variability and North Atlantic Jet: 
a multimodel view from the decadal climate prediction project. $\mathrm{J}$ Clim 34(1):347-360. https://doi.org/10.1175/JCLI-D-19-0981.1

Ruprich-Robert Y, Msadek R, Castruccio F, Yeager S, Delworth T, Danabasoglu G (2017) Assessing the climate impacts of the observed Atlantic multidecadal variability using the GFDL CM2.1 and NCAR CESM1 global coupled models. J Clim 30(8):27852810. https://doi.org/10.1175/JCLI-D-16-0127.1

Sanna A, Borrelli A, Athanasiadis P, Materia S, Storto A, Navarra A, Tibaldi S, Gualdi S (2016) CMCC-SPS3: the CMCC Seasonal Prediction System 3. CMCC Research Paper, RP0285

Scaife AA, Arribas A, Blockley E, Brookshaw A, Clark RT, Dunstone N, Eade R, Fereday D, Folland CK, Gordon M, Hermanson L, Knight JR, Lea DJ, MacLachlan C, Maidens A, Martin M, Peterson AK, Smith D, Vellinga M, Wallace E, Waters J, Williams A (2014) Skillful long-range prediction of European and North American winters. Geophys Res Lett 41(7):2514-2519. https:// doi.org/10.1002/2014GL059637

Schneider EK, Fennessy MJ, Kinter JL III (2009) A statistical-dynamical estimate of winter ENSO teleconnections in a future climate. $\mathbf{J}$ Clim 22(24):6624-6638. https://doi.org/10.1175/2009JCLI3147.1

Shaman J (2014) The seasonal effects of ENSO on European Precipitation: observational analysis. J Clim 27(17):6423-6438. https://doi. org/10.1175/JCLI-D-14-00008.1

Soulard N, Lin H, Yu B (2019) The changing relationship between ENSO and its extratropical response patterns. Sci Rep 9(1):1-10. https://doi.org/10.1038/s41598-019-42922-3

Taguchi M, Hartmann DL (2006) Increased occurrence of stratospheric sudden warmings during El Niño as simulated by WACCM. J Clim 19(3):324-332. https://doi.org/10.1175/JCLI3655.1

Timmermann A, An SI, Kug JS, Jin FF, Cai W, Capotondi A, Cobb KM, Lengaigne M, McPhaden MJ, Stuecker MF, Stein K, Wittenberg AT, Yun KS, Bayr T, Chen HC, Chikamoto Y, Dewitte B, Dommenget D, Grothe P, Guilyardi E, Ham YG, Hayashi M, Ineson S, Kang D, Kim S, Kim W, Lee YL, Li T, Luo JJ, McGregor S, Planton Y, Power S, Rashid H, Ren HL, Santoso A, Takahashi K, Todd A, Wang G, Wang G, Xie R, Yang WH, Yeh SW, Yoon J, Zeller E, Zhang X (2018) El Niño-Southern Oscillation complexity. Nature 559(7715):535-545. https://doi.org/10. 1038/s41586-018-0252-6

Toniazzo T, Scaife AA (2006) The influence of ENSO on winter North Atlantic climate. Geophys Res Lett 33(24):5-6. https://doi.org/10. 1029/2006GL027881

Trascasa-Castro P, Maycock AC, Scott Yiu YY, Fletcher JK (2019) On the linearity of the stratospheric and Euro-Atlantic sector response to ENSO. J Clim 32(19):6607-6626. https://doi.org/10. 1175/JCLI-D-18-0746.1

Trenberth KE (1997) The definition of El Niño. Bull Am Meteor Soc 78:2771-2778. https://doi.org/10.1175/1520-0477(1997)078\% 3c2771:TDOENO\%3e2.0.CO;2

Trenberth KE, Fasullo JT (2013) An apparent hiatus in global warming? Earth's Future 1(1):19-32. https://doi.org/10.1002/2013E F000165
Trenberth KE, Branstator GW, Karoly DJ, Kumar A, Lau NC, Ropelewski C (1998) Progress during TOGA in understanding and modeling global teleconnections associated with tropical sea surface temperatures. J Geophys Res Oceans 103(C7):1429114324. https://doi.org/10.1029/97JC01444

Voldoire A, Saint-Martin D, Sénési S, Decharme B, Alias A, Chevallier M, Colin J, Guérémy JF, Michou M, Moine MP, Nabat P, Roehrig R, Salas Mélia D, Séférian R, Valcke S, Beau I, Belamari S, Berthet S, Cassou C, Cattiaux J, Deshayes J, Douville H, Ethé C, Franchistéguy L, Geoffroy O, Lévy C, Madec G, Meurdesoif Y, Msadek R, Ribes A, Sanchez-Gomez E, Terray L, Waldman R (2019) Evaluation of CMIP6 DECK experiments with CNRMCM6-1. J Adv Model Earth Syst 11(7):2177-2213. https://doi.org/ 10.1029/2019MS001683

Wang C (2004) ENSO, Atlantic climate variability, and the Walker and Hadley circulations. In: The Hadley circulation: Present, past and future. Springer, pp 173-202. https://doi.org/10.1007/ 978-1-4020-2944-8 7

Wang L, Chen W, Huang R (2008) Interdecadal modulation of PDO on the impact of ENSO on the east Asian winter monsoon. Geophys Res Lett. https://doi.org/10.1029/2008GL035287

Weisheimer A, Schaller N, O'Reilly CH, MacLeod DA, Palmer T (2017) Atmospheric seasonal forecasts of the twentieth century: multi-decadal variability in predictive skill of the winter North Atlantic Oscillation (NAO) and their potential value for extreme event attribution. Q J R Meteorol Soc 143(703):917-926. https:// doi.org/10.1002/qj.2976

Yeh SW, Cai W, Min SK, McPhaden MJ, Dommenget D, Dewitte B, Collins M, Ashok K, An SI, Yim BY, Kug JS (2018) ENSO atmospheric teleconnections and their response to greenhouse gas Forcing. Rev Geophys 56(1):185-206. https://doi.org/10.1002/ 2017RG000568

Yu B, Zwiers FW (2007) The impact of combined ENSO and PDO on the PNA climate: a 1,000-years climate modeling study. Clim Dyn 29(7-8):837-851. https://doi.org/10.1007/s00382-007-0267-4

Zanchettin D, Franks SW, Traverso P, Tomasino M (2008) On ENSO impacts on European wintertime rainfalls and thier modulation by the NAO and the Pacific multi-decadal variability described through the PDO index. Int J Climatol 28(8):995-1006. https:// doi.org/10.1002/joc.1601

Zhang R, Delworth TL (2007) Impact of the Atlantic multidecadal oscillation on North Pacific climate variability. Geophys Res Lett. https://doi.org/10.1029/2007GL031601

Zhang Y, Wallace JM, Battisti DS (1997) ENSO-like interdecadal variability: 1900-93. J Clim 10(5):1004-1020. https://doi.org/ 10.1175/1520-0442(1997)010\%3c1004:ELIV\%3e2.0.CO;a2

Publisher's Note Springer Nature remains neutral with regard to jurisdictional claims in published maps and institutional affiliations. 